\title{
Hydrodynamics of a periodically wind-forced small and narrow stratified basin: a large-eddy simulation experiment
}

\author{
Hugo N. Ulloa ${ }^{1} \cdot$ George Constantinescu $^{2} \cdot$ Kyoungsik Chang $^{3}$. \\ Daniel Horna-Munoz ${ }^{2,4}$. Oscar Sepúlveda Steiner ${ }^{1}$. Damien Bouffard ${ }^{5}$. \\ Alfred Wüest ${ }^{1,5}$
}

Received: 6 April 2018 / Accepted: 29 October 2018 / Published online: 21 November 2018

(c) Springer Nature B.V. 2018

\begin{abstract}
We report novel results of a numerical experiment designed for examining the basin-scale hydrodynamics that control the mass, momentum, and energy distribution in a daily windforced, small thermally-stratified basin. For this purpose, the 3-D Boussinesq equations of motion were numerically solved using large-eddy simulation (LES) in a simplified (trapezoidal) stratified basin to compute the flow driven by a periodic wind shear stress working at the free surface along the principal axis. The domain and flow parameters of the LES experiment were chosen based on the conditions observed during summer in Lake Alpnach, Switzerland. We examine the diurnal circulation once the flow becomes quasi-periodic. First, the LES results show good agreement with available observations of internal seiching, boundary layer currents, vertical distribution of kinetic energy dissipation and effective diffusivity. Second, we investigated the wind-driven baroclinic cross-shore exchange. Results reveal that a near-resonant regime, arising from the coupling of the periodic windforcing $(T=24 \mathrm{~h})$ and the $\mathrm{V} 2 \mathrm{H} 1$ basin-scale internal seiche $\left(T_{\mathrm{V} 2 \mathrm{H} 1} \approx 24 \mathrm{~h}\right)$, leads to an active cross-shore circulation that can fully renew near-bottom waters at diurnal scale. Finally, we estimated the bulk mixing efficiency, $\Gamma$, of relevant zones, finding high spatial variability both for the turbulence intensity and the rate of mixing $\left(10^{-3} \leq \Gamma \leq 10^{-1}\right)$. In particular, significant temporal variability along the slopes of the basin was controlled by the periodic along-slope currents resulting from the V2H1 internal seiche.
\end{abstract}

Keywords Large-eddy simulation $\cdot$ Basin-scale circulation $\cdot$ Resonance regime $\cdot$ Crossshore exchange

\section{Introduction}

Wind is the primary forcing mechanism responsible for transport processes in stratified lakes $[6,78]$. Wind stress acting on the water surface drives baroclinic responses in ens closed stratified basins $[12,38]$, which can lead to a variety of hydrodynamically-controlled

Hugo N. Ulloa

hugo.ulloa@epfl.ch

Extended author information available on the last page of the article 
phenomena. These phenomena can span from basin-scale internal waves $[2,41,55,60]$ and upwelling/downwelling motions $[59,62]$, to localized and intermittent turbulence and mixing episodes in the interior of the stratified waterbody $[9,52]$, including the near-sediment bottom [19, 21, 24, 30, 32, 33]. Numerical models able to capture the afore-mentioned hydrodynamic processes and their interactions are needed to explore the physics of the aquatic ecosystems.

One of the main challenge in modelling stratified lakes is the scale separation between basin-scale motions and the much smaller scale processes that control, for instance, boundary layers, nonlinear dynamics, and turbulence [23]. The widely-used Reynolds-averaged Navier-Stokes (RANS) based models include transport equations for one or multiple turbulence variables needed to estimate the eddy viscosity. Modeling is employed in these transport equations to approximate the various terms (e.g., energy dissipation). In particular, boundary friction is usually parametrized via drag or damping coefficients and relies on the law-of-the-wall framework. Yet, near bottom flows can substantially differ from logarithmic velocity profiles, depending on the flow dynamics [31]. Moreover, most of the numerical hydrodynamic studies of real-scale stratified lakes rely on hydrostatic models capable to reproduce the fundamental basin-scale motions that regulate the horizontal transport [22]. However, the hydrostatic assumption becomes arguable at smaller scales, especially when internal oscillations are subject to nonlinearities [13, 69, 74] or when baroclinic flows interact with the topography $[5,15,16]$.

As high-performance computer power increases and parallel computing algorithms allow better scalability, one can use finer meshes that provide higher flow resolution. Also, more sophisticated, but computationally much more expensive, turbulence modeling approaches can be adopted to resolve the energetically important turbulent eddies controlling transport and mixing. Such methods, which include large-eddy simulation (LES) and hybrid RANS-LES approaches like Detached Eddy Simulation, are successfully used to predict flow and transport at lab-scale and, more recently, at field-scale for geosciences applications [14, 28, 29, 45, 54]. LES was recently used by Santo et al. [56] to investigate wind-driven circulation in Lake Ledro (Italy) under nearly absent stratification. Despite the lack of observations in Lake Ledro to assess the accuracy of the numerical model predictions, their results showed reasonable agreement with reference ranges of eddy diffusivities and dissipation rates estimated in similar aquatic systems.

In this work, we report novel results of a 3-D LES numerical experiment designed to examine in detail the hydrodynamics of an idealized stratified basin forced by a periodic wind-induced shear stress at the free surface.

The goal of the present LES study is to provide a spatio-temporal characterization of the basin-scale circulation resulting from a near-resonant regime between diurnal winds and basin-scale internal waves in a small stratified lake. To assess the performance of our numerical model, we considered the scales and stratification observed during the summer season in Lake Alpnach, Switzerland. This lake has been the object of several field studies [32, 33, 41], including a real-scale RANS-based numerical study by Becherer and Umlauf [3]. Observations show that the 2nd vertical and 1 st horizontal internal-seiche mode (V2H1) is the dominant hydrodynamic feature observed in Lake Alpnach during the summer (see Fig. 1). Becherer and Umlauf [3] investigated the boundary mixing above the sloping sediment in Lake Alpnach focusing on the shear-induced convection driven by bottom boundary layer (BBL) currents (right schematic in Fig. 1). Their numerical simulation showed good agreement with the available field observations [33] and BBL dynamics [32]. We use the work of Becherer and Umlauf [3] as a starting point to formulate a simplified numerical 


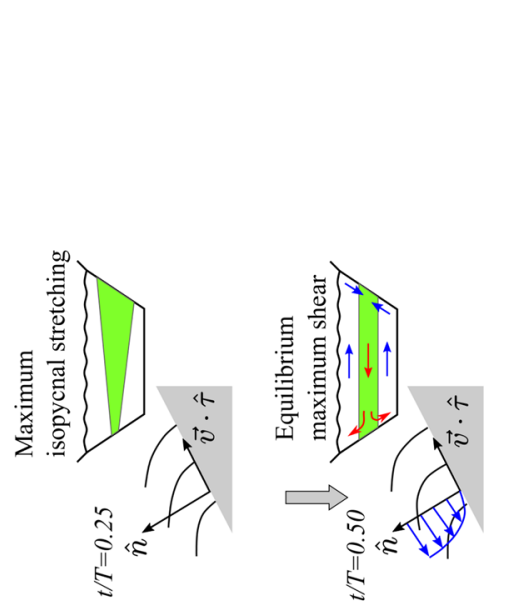

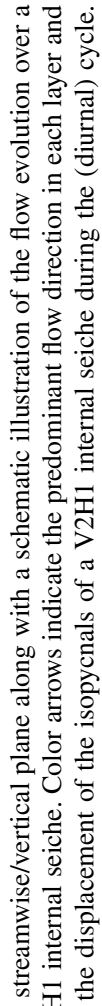
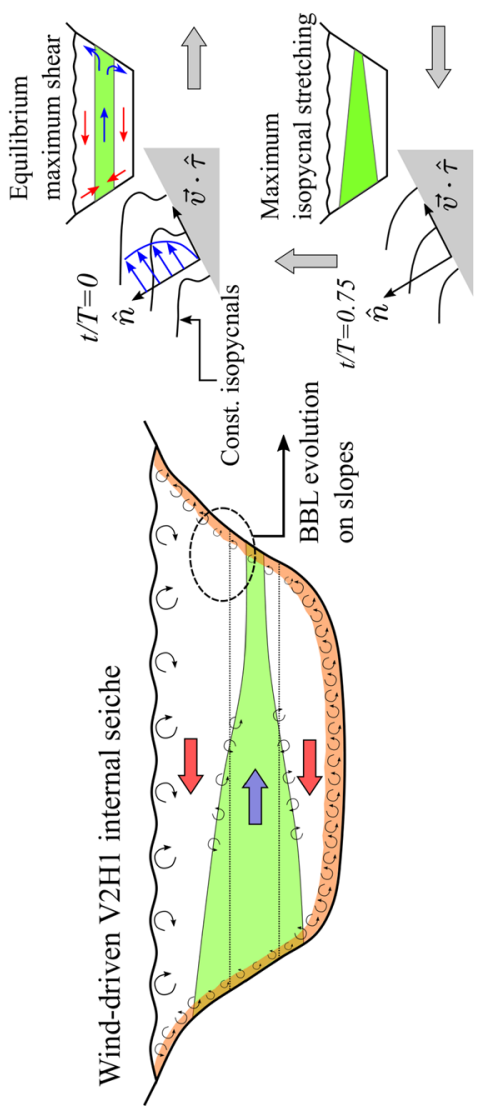

焉要通

$\Xi$ :

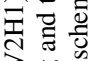

$\sum^{\infty}, 5$

记

空

플

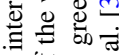

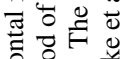

윰

월

苛志

च

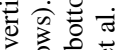

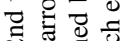

긍

on $:$

完㝋专

$>$ 옹

记

范

区 进

क व 0

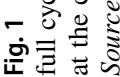


experiment able to reproduce the main hydrodynamics processes. However, unlike Becherer and Umlauf [3], we concentrate on analyzing the wind-driven baroclinic circulation, linking basin-scale internal flows with near-bottom flow patterns. In particular, we investigate the mass exchange between nearshore and offshore regions resulting from the baroclinic circulation; this information is crucial to estimate flushing timescales of nearshore waters. Finally, we examine the spatio-temporal energy distribution at diurnal scale to identify zones where turbulence intensity and mixing processes are potentially enhanced by the hydrodynamics within the stratified basin.

Overall, this study aims at showing that LES is a powerful approach to investigate fundamental physical processes in small stratified basins and that such studies are directly relevant for understanding the physics of stratified waters.

\section{Formulation}

\subsection{Equations of motion}

The Boussinesq approximation is employed to account for stratification effects in a finite-volume viscous solver [10]. The Navier-Stokes and density transport equations are solved in nondimensional form with a length scale $D$, velocity scale $U$, and timescale $D / U$. The filtered continuity, momentum and density transport equations are:

$$
\begin{gathered}
\nabla \cdot \mathbf{v}^{\prime}=0, \\
\frac{D \mathbf{v}^{\prime}}{D t^{\prime}}=-\nabla \phi^{\prime}+\nabla\left(\left[\frac{1}{\operatorname{Re}}+v_{s g s}\right] \nabla \mathbf{v}^{\prime}\right)-\frac{\rho^{\prime}}{\operatorname{Fr}^{2}} \hat{\mathbf{k}}, \\
\frac{D \rho^{\prime}}{D t^{\prime}}=\nabla\left(\left[\frac{1}{\operatorname{Re} \operatorname{Pr}}+\kappa_{s g s}\right] \nabla \rho^{\prime}\right),
\end{gathered}
$$

where $\mathbf{v}^{\prime}=\left(u^{\prime}, v^{\prime}, w^{\prime}\right)$ is the filtered nondimensional velocity vector in a Cartesian system, $\phi^{\prime}$ is the nondimensional pressure, $t^{\prime}$ is the nondimensional time, and $\left(x^{\prime}, y^{\prime}, z^{\prime}\right)$ are the coordinates in the streamwise, spanwise, and vertical direction, respectively. $\hat{\mathbf{k}}$ is the unit vector along $z^{\prime}$. The nondimensional density is defined as $\rho^{\prime}=\left(\rho-\rho_{1}\right) /\left(\rho_{2}-\rho_{1}\right)$, where $\rho$ is the dimensional density, $\rho_{1}$ and $\rho_{2}$ are the minimum and maximum density, respectively, in the density field at the start of the simulation. The three parameters in (1) are the Reynolds number, $R e \equiv U D / \nu$, the square Froude number, $F r^{2} \equiv U^{2} /\left(D g \Delta \rho / \rho_{1}\right)$, and the Prandtl number, $\operatorname{Pr} \equiv \nu / \kappa$, where $v$ and $\kappa$ are the molecular viscosity and thermal diffusivity, respectively, $g$ is the gravitational acceleration, and $\Delta \rho=\rho_{2}-\rho_{1}$. The other variables in the (filtered) governing equations are the subgrid-scale viscosity, $v_{s g s}$, and the subgrid-scale diffusivity, $\kappa_{s g s}$. Note we do not include Coriolis acceleration in the momentum equation (1b) since our study case is based on a small and narrow stratified basin. In fact, the Rossby radius of deformation for the dominant basin-scale internal modes V2H1 $\left(c \approx 0.093 \mathrm{~m} \mathrm{~s}^{-1}\right)$ is $R_{o}=c / f \approx 900 \mathrm{~m}\left(f=1.063 \times 10^{-4} \mathrm{~s}^{-1}\right)$ and the mean width of Lake Alpnach is $W \approx 1000 \mathrm{~m}[3,33]$. For the above length scales, the characteristic Burger number, $S \equiv R_{o} /(W / 2) \approx 1.8$, shows that Earth's rotation plays a secondary role in the basinscale dynamics and has negligible effects in smaller scale motions $[1,26]$. 


\subsection{Numerical method and solver validation studies}

The conservative form of the (filtered) equations of motion (1) are advanced in time using a semi-implicit iterative method [47]. The pressure field is computed by solving the Poisson equation using a multigrid algorithm to accelerate convergence [47]. All operators in the momentum and pressure equations are discretized using second-order central schemes. The algorithm is second-order accurate in time and discretely conserves energy $[35,47]$. Eddy viscosity and eddy diffusivity are estimated from the resolved velocity and density fields using the dynamic Smagorinsky model [47] that eliminates the need to include any correction for stratification effects and near-wall damping functions in the model. Discrete energy conservation ensures robustness at relatively high Reynolds numbers. The Quadratic Upstream Interpolation for Convective Kinematics (QUICK) scheme is used to discretize the advective term in the transport equation for the density. The solver is implemented in Fortran 90 and is parallelized using Message Passing Interface.

The solver has been used and validated for a wide class of stratified turbulent flows. For instance, Chang et al. $[10,11]$ simulated turbulent channel flow containing a bottom 2-D cavity and ejection of buoyant and negatively-buoyant contaminants from the cavity. The code was also shown to accurately predict gravity current flows and internal bores in reservoirs and channels. Validations are reported in Ooi et al. [43] and Tokyay et al. [65-68] for bottom propagating currents over flat and deformed terrain, in Steenhauer et al. [63] for gravity currents over sloped boundaries, in Ooi et al. [42] and Yuksel-Ozan et al. [80] for intrusion and free surface currents, and in Borden et al. [7] for internal bores forming in layered systems. Additionally, validation of the solver for predicting mixing and transport is discussed in Pierce and Moin [48] for reacting flows that require solving advection-diffusion equations for passive and non-passive scalars, and in Sommer et al. [61] to explain the mechanism whereby upward-swimming bacteria could induce mixing in a meromictic lake.

\subsection{Computational domain, boundary and initial conditions}

Figure 2 shows the computational domain in the $x-z$ plane. The basin has a trapezoidal shape whose maximum depth is $D=40 \mathrm{~m}$. The slopes of the lateral bottom boundaries are approximately $2^{\circ}$ and are extended from shore to the interior along $30 \mathrm{D}$, while the length of the flat bottom part is $60 \mathrm{D}$. The basin length at the top boundary is $120 \mathrm{D}$, which corresponds to the maximum horizontal extent of the lake along the direction of the dominant winds. The geometry and magnitudes represent roughly the bathymetry of Lake Alpnach in the streamwise-vertical plane. The length of the domain in the spanwise direction ( $y$-axis) in which the flow is assumed to be homogeneous is $1.6 \mathrm{D}$. As a velocity scale, we chose $U=0.05 \mathrm{~m} \mathrm{~s}^{-1}$, which is close to the maximum magnitude of the wind-driven velocities observed in Lake Alpnach for diurnal winds whose magnitude is of the order of $1-10 \mathrm{~m} \mathrm{~s}^{-1}$.

The bottom basin was treated as a no-slip boundary. In contrast, the top rigid-lid surface was treated as a slip boundary on which a periodic shear stress $\tau=\tau_{0} \sin (2 \pi t / T)$ was imposed in the streamwise direction to mimic the wind-induced stress pattern observed in Lake Alpnach [33, 41]. The shear stress on the spanwise direction and the vertical velocity at the top boundary were set equal to zero,

$$
\mathbf{v}^{\prime}(\mathbf{x})=0, \quad \mathbf{x} \in \text { Bottom }
$$




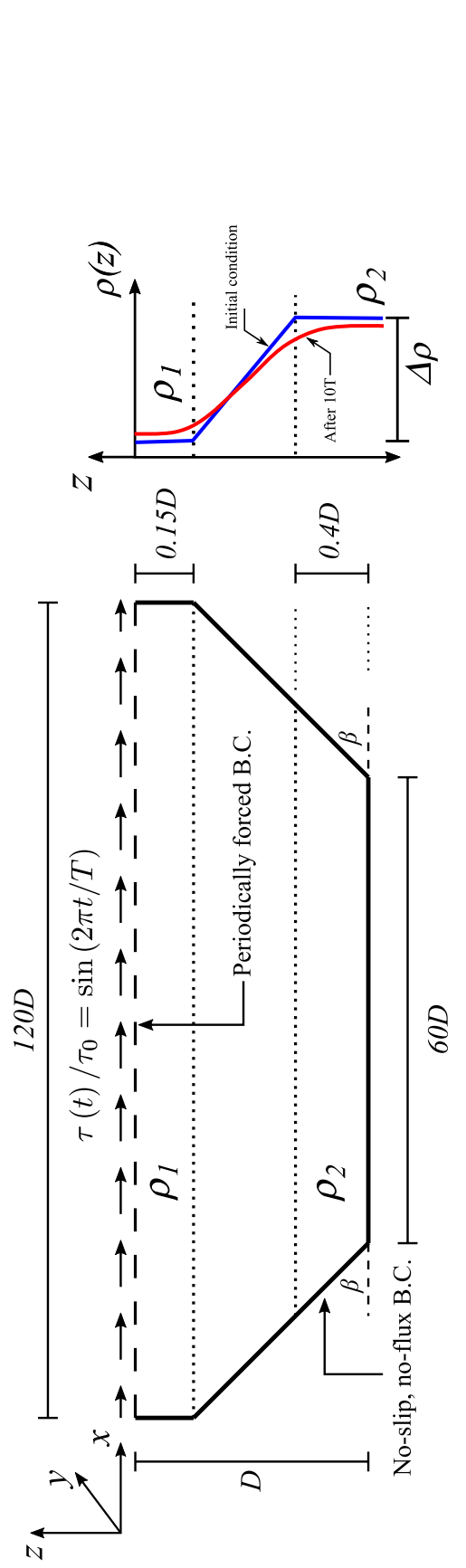

灵灵异

ㄷ. 옹

हี 范

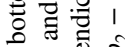

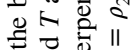

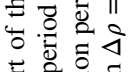

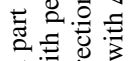

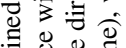

远导

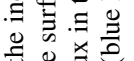

氙造递

叁导总

क

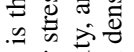

(ิ) 형

욜

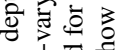

छ 0 . क

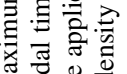

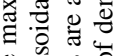

巳.

两进

:

冚芯矛

ठ 키

त

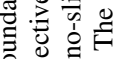

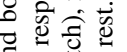

ज.

竞苞导

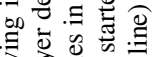

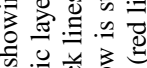

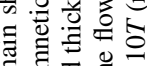

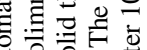

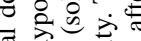

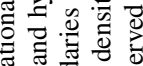

늘응

형

品造要

衣云这

㟧

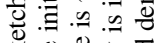

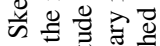

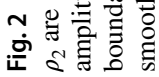




$$
\mu \frac{\partial u^{\prime}}{d z}=\tau(t), \quad \mu \frac{\partial v^{\prime}}{d z}=0 \quad \text { and } \quad w^{\prime}=0 \quad \text { at } \quad z=0 .
$$

The period of the forcing was $T=24 \mathrm{~h}$ or $100 \mathrm{D} / U$ and the maximum amplitude of the shear stress was $\tau_{0} / \rho_{1}=0.009 U^{2}$. This value corresponds to oscillatory winds with a peak speed of about $4 \mathrm{~m} \mathrm{~s}^{-1}$. In the case of the density field, the density gradient on the direction normal to the solid wall and top boundary was set to zero,

$$
\frac{d \rho^{\prime}}{d \hat{\mathbf{n}}}=0
$$

Additionally, periodic boundary condition were applied for all variables at the spanwise lateral boundaries.

The flow was initially at rest, aside from a small 3-D random disturbance of amplitude $0.03 U$ that was imposed on all three velocity components in the top layer (epilimnion). Considering the summer stratification observed in Lake Alpnach, a three-layer vertical stratification with a wide linear transition (metalimnion) from the epilimnion to the deep layer (hypolimnion) was assumed in the basin at the start of the simulation (Fig. 2). The initial density of the hypolimnion of height $0.4 D$ was assumed to be constant, $\rho_{2}=999.99$ $\mathrm{kg} \mathrm{m}^{-3}$, and corresponds to a temperature of $6{ }^{\circ} \mathrm{C}$. The density difference between the hypolimnion and the epilimnion was $\Delta \rho=1.0 \mathrm{~kg} \mathrm{~m}^{-3}$. The temperature of the epilimnion of height $0.15 D$ was $\sim 16{ }^{\circ} \mathrm{C}$.

The simulation was run on a high-performance PC cluster on 128 processors, with a molecular Prandtl number equal to $\operatorname{Pr}=6$, a Reynolds number $\operatorname{Re}=10^{5}$, and a square Froude number corresponding to mild forcing conditions $\mathrm{Fr}^{2}=1 / 160$. The grid contained over 17 million nodes, with 64 grid points in the spanwise direction to effectively simulate vortex stretching and thus the dynamics of the energetically important eddies in the flow and their effect on transport and mixing.

The typical cell size was close to $0.025 D$ in all three directions. The vertical mesh was refined near the bottom and top boundaries. To resolve the wind-driven unsteady boundary layer and BBL currents, the vertical cell size was equally decreased to about $0.001 \mathrm{D}$ close to the top (free surface) and flat bottom boundaries. For this parameterization, the time step was $0.002 D / U$. The simulation was run until the velocity and density flow fields became quasi-periodic. Based on examination of the 2-D contour plots of the spanwise-averaged velocity and density fields and of velocity and density time series at selected points inside the basin, the quasi-periodic regime was achieved after 7 cycles $(t=7 T)$. One should mention that a fully periodic regime cannot be reached in a system where the background stratification is changing with time and the flow is turbulent. The above is the case in our numerical experiment. For $t>7 T$, the density profile becomes smoother but retains a three-layer structure. Figure 2 shows the density profile after time averaging over the ninth cycle. The hydrodynamics is analyzed over a full cycle, $9 T \leq t \leq 10 T$, after the solution is found in a quasi-periodic regime, while statistics are computed over $8 T \leq t \leq 10 T$.

The length-scale associated with the transition to stratified turbulence is the Ozmidov scale, $L_{O} \equiv \sqrt{\varepsilon / N^{3}}$, and represents the scale at which the buoyant forces balance the inertial forces. In highly energetic and weakly stratified regions, such as the epilimnion and within the BBL zone (e.g., $10^{-8} \leq \varepsilon \leq 10^{-7} \mathrm{~W} \mathrm{~kg}^{-1}, N^{2} \approx 10^{-5} \mathrm{~s}^{-2}$ ), the Ozmidov lengthscale ranges $0.5 \leq L_{O} \leq 2 \mathrm{~m}$. Yet, as the stratification becomes stronger and the intensity of turbulence weaker in the interior and mid-depth zones (e.g., $10^{-11} \leq \varepsilon \leq 10^{-9} \mathrm{~W} \mathrm{~kg}^{-1}$, $N^{2} \approx 10^{-4} \mathrm{~s}^{-2}$ ), $L_{O}$ gets substantially smaller, $10^{-3} \leq L_{O} \leq 10^{-2} \mathrm{~m}$. In this scenario, our 
vertical resolution can resolve $L_{O}$ in the epilimnion and in the deepest BBL regions but is not able to resolve $L_{O}$ at mid-depth and interior zones where stratification can shrink $L_{O}$ to milimeters. Resolving these length scales is not yet possible in a real basin and is out of scope of this work.

\section{Basin-scale hydrodynamics processes}

In this section, we examine three fundamental hydrodynamic processes that have been quantified via observations, thus providing a robust benchmark for evaluating the performance of the numerical model: (1) wind-driven flow and basin-scale internal waves, (2) stratified shear flows, and (3) bottom boundary layer currents.

\subsection{Wind-driven flow and basin-scale oscillations}

Figure 3 shows the diurnal phase (equivalent to a full wind-forcing cycle) of the Boussinesq density field, $\rho$, overlaid by isopycnals (grey-lines), along with the streamwise flow component, $u$, overlaid by streamlines (black-lines) in a streamwise-vertical plane $(x-z)$. Although a range of different baroclinic oscillations compounds the flow evolution, the spatio-temporal signature of $\rho$ is mostly attributed to the V2H1 mode [41]. This particular basin-scale internal seiche is characterized by a three-layer density response (see left panels in Fig. 3). In this case, the epilimnion and hypolimnion oscillate against each other, squeezing and stretching the metalimnion alternately as is schematized in Fig. 1. The V2H1 mode is, at the same time, associated with a three-layer lateral flow circulation (see right panels in Fig. 3). However, it is relevant to mention that $u$ shows a fourth top layer, thinner than the deeper ones. Indeed, the thickness of this top layer is strongly modulated by the surface wind stress. These three- and four-layer patterns in the streamwise flow are consistent with observations in Lake Alpnach during the summer (see Fig. 14b in Appendix 1, specifically at days 229 and 232).

We investigate the normal modes and the natural frequencies of our system for classifying the internal wave field. To do so, we resolve a generalized 2-D eigenvalue problem of the type $[18,73]$

$$
\mathbf{A} \Phi=\omega^{2} \mathbf{B} \Phi .
$$

Here, $\Phi$ establishes the spatial structure of the stream function, $\mathbf{A}$ is a matrix that characterizes its streamwise discretization, and $\mathbf{B}$ is a matrix that characterizes the vertical discretization, including the background stratification $N_{*}^{2}(z)$ of the basin (see Fig. 4a). The above formulation assumes periodic normal modes whose temporal structure is set by the frequency $\omega$. The 2-D normal mode framework and its boundary conditions is detailed in Appendix 2.

Figure $4 \mathrm{~b}-\mathrm{e}$ illustrate four different normal modes for the trapezoidal stratified basin (stream function, $\Phi(x, z)$, velocity field, $u=-\partial \Phi / \partial z$ and $w=\partial \Phi / \partial x$, and period) including the $\mathrm{V} 2 \mathrm{H} 1$ internal seiche, $\mathrm{V} 3 \mathrm{H} 1, \mathrm{~V} 3 \mathrm{H} 3$, and the $\mathrm{V} 4 \mathrm{H} 2$ mode, respectively. We found that the mode $\mathrm{V} 2 \mathrm{H} 1$ has a period close to $24 \mathrm{~h}$ (Fig. $4 \mathrm{~b}$ ), making it a candidate to resonate with the diurnal wind-forcing. The mode $\mathrm{V} 3 \mathrm{H} 1$, in contrast, has a period of $36.62 \mathrm{~h}, 1.5$ times the wind-forcing period, and is characterized by a four-layer structure (see arrows in Fig. 4c). Although a full phase of the V3H1 cannot be resolved during one diurnal cycle, the vertical signature of $\mathrm{V} 3 \mathrm{H} 1$ is identified in the streamwise velocity, $u$, throughout the 


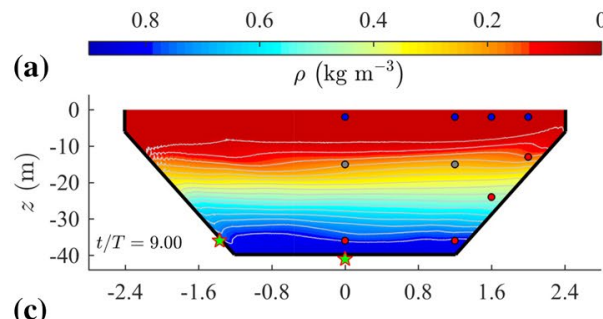

(c)
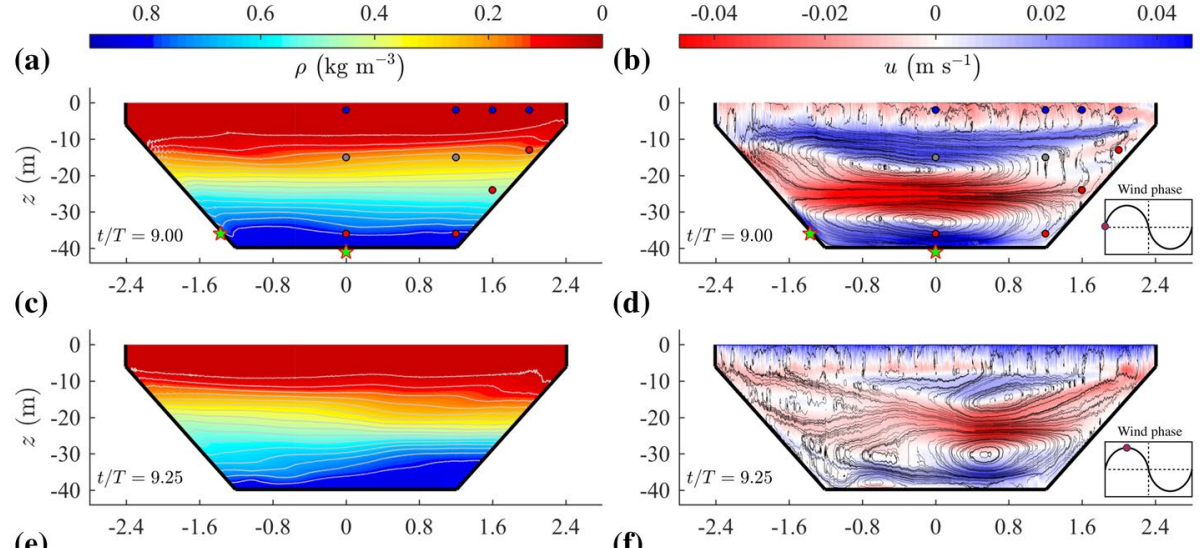

(d)
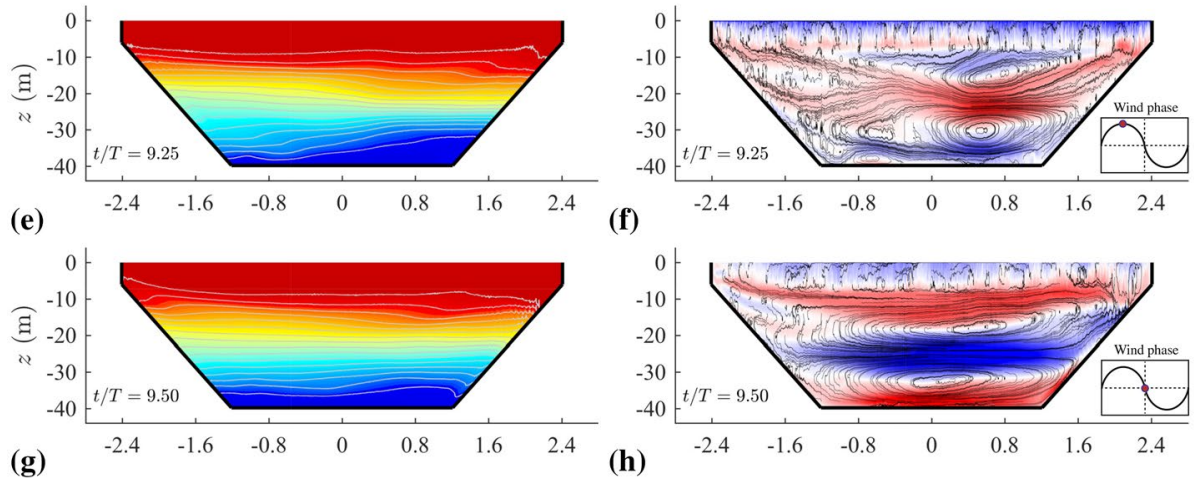

(f)

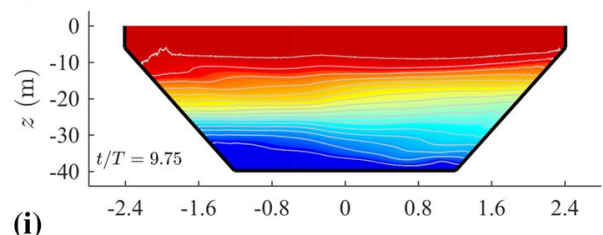

(h)
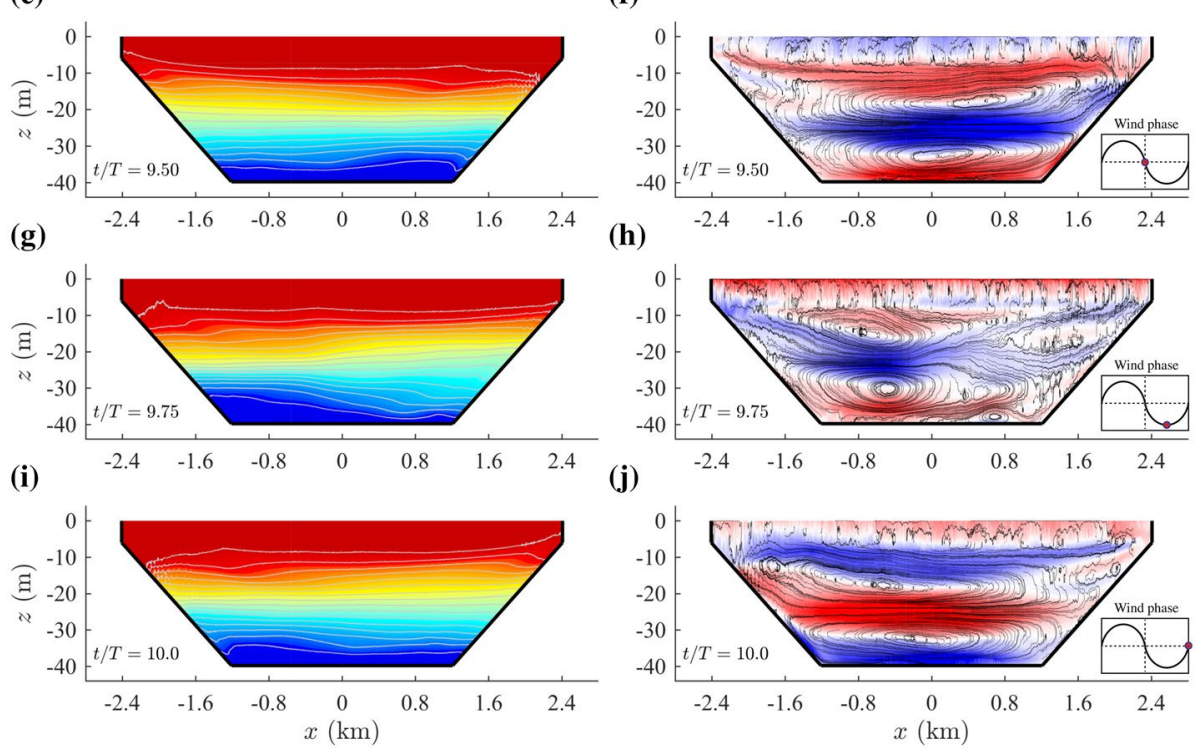

(j)

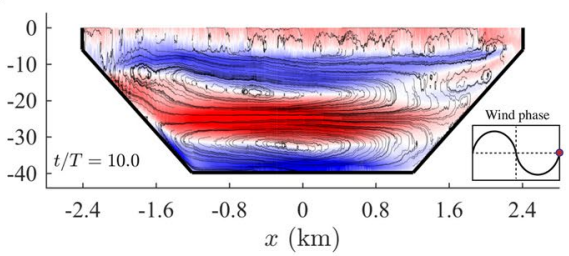

Fig. 3 Visualization of the near-resonant wind-driven V2H1 internal seiche in a $x-z$ plane over a full diurnal cycle at $t / T \in\{9 ; 9.25 ; 9.5 ; 9.75 ; 10\}: \mathbf{a}, \mathbf{c}, \mathbf{e}, \mathbf{g}, \mathbf{i}$ structure of Boussinesq density field, $\rho$ (difference between the total density and reference density $\rho_{1}$ ), and isopycnals (grey lines); $\mathbf{b}, \mathbf{d}, \mathbf{f}, \mathbf{h}, \mathbf{j}$ crossshore velocity component, $u$, along with 2-D streamlines (black lines). Green-star and circle markers on panels $\mathbf{a}, \mathbf{b}$ show the position of points where the temporal variations of relevant variables are analyzed in Figs. 5 and 7

diurnal phase (right panels in Fig. 3). Additionally, the modes V3H3 and V4H2 (Fig. 4d, e) show localized circulation patterns that might arise in the stratified basin. Indeed, similar localized circulations are shown in Fig. 3d, h. Determining the normal modes allows the interpretation and classification of the primary frequencies identified from spectral analysis. Table 1 summarizes the theoretical periods of the principal normal modes.

Visual inspection of the density field suggests that the wavefield structure might vary from surface to deeper regions. To identify the primary constituents of the internal gravity wavefield, we computed the power spectral density (PSD) of the locally-defined potential 


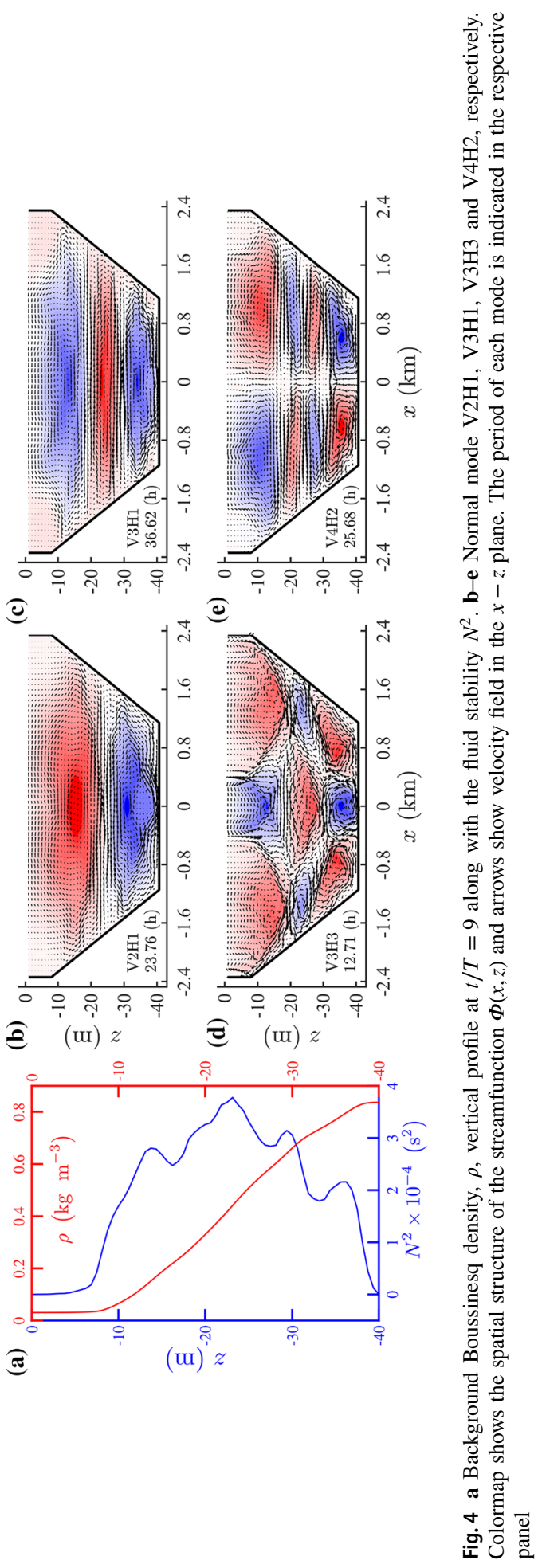


Table 1 Periods of the theoretical normal modes in the stratified trapezoidal basin

\begin{tabular}{llll}
\hline $\begin{array}{l}\text { Basin-scale } \\
\text { normal modes }\end{array}$ & Period $(\mathrm{h})$ & $T_{m} / T(-)$ & Observed in PSD \\
\hline V1H1 & 10.47 & $\sim 0.4$ & Yes \\
V2H1 & 23.76 & $\sim 1.0$ & Yes \\
V3H1 & 36.62 & $\sim 1.5$ & Not solved \\
V3H3 & 12.71 & $\sim 0.5$ & Yes \\
V4H2 & 25.68 & $\sim 1.0$ & Yes \\
\hline
\end{tabular}

energy, $\operatorname{PE}\left(\rho / \rho_{1}\right) g H$, and kinetic energy, $\operatorname{KE}\left(\rho / \rho_{1}\right) \mathbf{v}^{2} / 2$, per unit mass, at three different zones. We have chosen a near-surface depth, a mid-depth, and near-bottom depths to examine the wavefield in the epilimnion, the metalimnion, and the BBL zone, respectively. The specific spatial extents of the epilimnion, the metalimnion and the BBL are characterized in the next section. The PSDs were calculated using time series that included two windforcing periods $(48 \mathrm{~h}$ ) sampled with a time interval of $\Delta t=1.7 \mathrm{~s}$ from ten different positions marked in Fig. 3a, b by blue, grey and red spots. Four PSDs were obtained from the epilimnion zone (blue spots), two PSDs from the metalimnion zone (grey spots), and four PSDs from the BBL (red spots). Then, from each zone, we computed an averaged PSD.

We stress the significant differences between the PE PSDs shown in Fig. 5a-c. In the epilimnion, no energy peaks are observed as a result of the weak density fluctuations in this region (Fig. 5d). In the case of the metalimnion, higher energy peaks are found in response to a more active internal wavefield and higher density gradients (Fig. 5e). In this zone, the primary energy peak is attributed to the mode $\mathrm{V} 3 \mathrm{H} 3$ of $12 \mathrm{~h}$ period. However, the largest energy peak in the PE PSD is associated with the V2H1 of $\sim 24$ h period in the BBL region (Fig. 5f). The KE PSDs are subtly different from the PE PSDs. Yet, the largest energy peak in the KE PSDs is consistently found at $\sim 12 \mathrm{~h}$ in the three zones. Note that the $12 \mathrm{~h}$ peak in the KE PSDs corresponds to a $24 \mathrm{~h}$ period in the velocity field, $\mathbf{v}$, due to the KE definition, $K E \sim \mathbf{v}^{2}$. In consequence, PE and KE PSDs indicate that V2H1 is the main modal constituent and support the existence of a resonance regime between the V2H1 mode and the diurnal wind-forcing, as shown by Münnich et al. [41] for Lake Alpnach.

We emphasize the strong energy peak that the V2H1 mode has in the BBL zone compared to the metalimnion zone in the PE PSD. This result might be counter-intuitive, but in such a small and shallow basin the near-bottom density fluctuations, driven by vertical oscillations, can be substantially high [41]. The above process is especially relevant in zones where upslope-and-downslope flow seiching enhances the vertical fluid excursions. Contrary, density fluctuations in the metalimnion zone are expected to be weaker than BBL zones because of the second-vertical modal response.

\subsection{Shear flow stability}

We examine the fluid stability, $N^{2} \equiv-\left(g / \rho_{1}\right) \partial_{z} \rho$, and the gradient Richardson number, Ri, expressed inversely for convenience as

$$
\mathrm{Ri}^{-1} \equiv \frac{S^{2}}{|N|^{2}},
$$

to analyze the flow stability and identify the zones where supercritical shear flows are found. Here $S^{2} \equiv(\partial u / \partial z)^{2}+(\partial v / \partial z)^{2}$ is the square of the vertical shear. Scaling $\mathrm{Ri}^{-1}$ by 
(a) Epilimnion

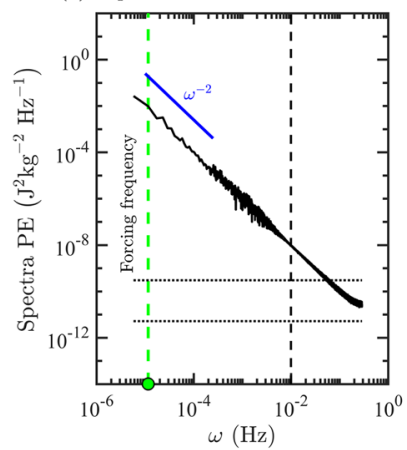

(d) Epilimnion

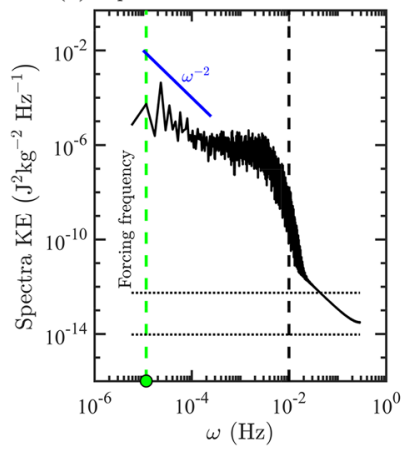

(b) Metalimnion

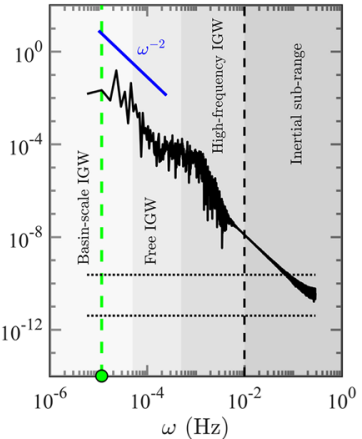

(e) Metalimnion

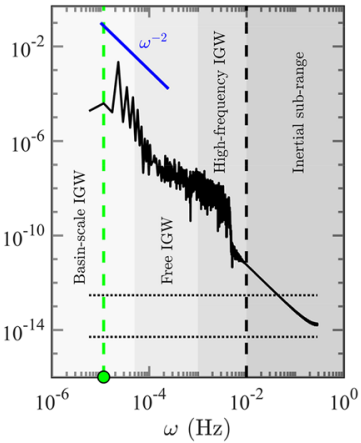

(c) $\mathrm{BBL}$

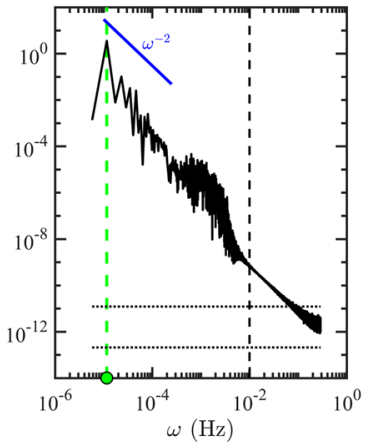

(f) $\mathrm{BBL}$

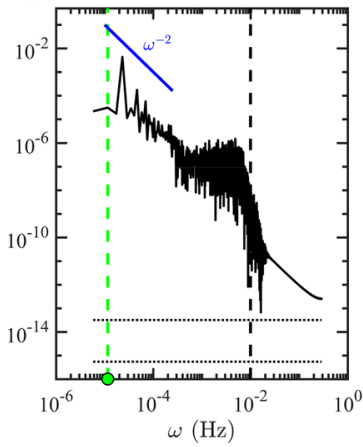

Fig. 5 Frequency spectra of potential energy, $\left(\rho / \rho_{0}\right) g h$, and the kinetic energy, $\left(\rho / \rho_{0}\right) \mathbf{v}^{2} / 2$, per mass unit, at a, $\mathbf{d}$ epilimnion, $z \approx-2 \mathrm{~m}$ (average of spectra calculated at four different horizontal positions in the surface mixed layer: blue circles in Fig. 3a, b; b,e metalimnion, $z \approx-15 \mathrm{~m}$ (average of spectra calculated at two different horizontal positions in the metalimnion layer: grey circles in Fig. 3a, b; and c,f upper bottom boundary layer, $h \approx 4 \mathrm{~m}$ (average of spectra calculated at four different horizontal positions within the BBL over the flat and the inclined parts of the bed: red circles in Fig. 3a, b. Blue curves denote the gravity spectrum slope, $\omega^{-2}$. The green circle denotes the forcing frequency $(24 \mathrm{~h}$ period). The dashed-line denotes the reference buoyancy frequency scale, $N_{0}=\sqrt{g\left(\Delta \rho / \rho_{1}\right) / D}$. Metalimnion spectra also show the internal gravity wave (IGW) subranges bounded by shaded areas. Confidence interval level at the $95 \%$ is given by the difference between the horizontal dotted lines

the critical gradient Richardson number, $\mathrm{Ri}_{\mathrm{c}}=1 / 4[25,37]$, we map the shear stability in space:

$$
\text { Shear flow stability : } \begin{cases}\log _{10}\left(\mathrm{Ri}_{\mathrm{c}} \mathrm{Ri}^{-1}\right)<0, & \text { subcritical, } \\ \log _{10}\left(\mathrm{Ri}_{\mathrm{c}} \mathrm{Ri}^{-1}\right)=0, & \text { critical, } \\ \log _{10}\left(\mathrm{Ri}_{\mathrm{c}} \mathrm{Ri}^{-1}\right)>0, & \text { supercritical. }\end{cases}
$$

One should stress that supercritical regimes are necessary but not sufficient to drive unstable stratified shear flows. The most robust fluid stability, $N^{2}$, is found between 10 and $30 \mathrm{~m}$ depth (see blueish color regions in Fig. 6a, c). This stable zone is bounded vertically by regions with weak or null stability, $N^{2} \approx 0$. The upper whitish zone characterizes the well-mixed epilimnion layer, whose extent can be defined by choosing a threshold of $N^{2}$. 
Based on time averages, $N^{2}=10^{-4} \mathrm{~s}^{-2}$ is found at $z_{E P I} \approx-5.5 \pm 1.1 \mathrm{~m}(z=0$ corresponds to the top free surface). The above implies that waters are, on average, reasonably wellmixed over the first 5-6 m below the free surface. Hence, the vertical shear driven by the wind stress leads to supercritical shear flow regimes in the epilimnion, $\log _{10}\left(\mathrm{Ri}_{\mathrm{c}} \mathrm{Ri}^{-1}\right)>0$ (upper reddish layer in Fig. 6b, d). Similarly, the well-mixed BBL results from the ability of near-bottom flows to stir and mix waters. Adopting the same threshold value used for defining the epilimnion, the BBL thickness on the flat part is $h \approx 2.5 \mathrm{~m}$, and decreases to almost $1 \mathrm{~m}$ as the BBL is exposed to more stable fluids at mid-depths. The increase of the BBL thickness from mid-depths to the deeper basin agrees with the cross-shore BBL variability observed by Gloor et al. [19] in Lake Alpnach.

The relationship between the stabilizing and destabilizing mechanisms is well captured by the shear flow stability, $\log _{10}\left(\mathrm{Ri}_{\mathrm{c}} \mathrm{Ri}^{-1}\right)$. In Fig. $6 \mathrm{a}$, b, we observe that during the strengthening wind-phase $(t / T=9$ to $t / T=9.25)$, there is a strong onshore metalimnetic flow (Fig. $3 \mathrm{~b}$ and the green arrows in Fig. 6a) that feeds both upslope and downslope flows along the inclined bathymetry. The intensity of the downslope current is high enough to generate a supercritical shear layer associated with unstable stratification (negative values of $N^{2}$ ) near the BBL. In the case of the upslope current, we observe a transition from subcritical shear flows and stable stratification, at the core of metalimnetic depths, to supercritical shear flows with the emergence of density overturns at the current front. After half a wind-forcing period, $t / T=9.5$ (Fig. 6c, d), the baroclinic adjustment leads to strong downslope flows from mid-depth waters and upslope flows from deeper waters. This fluid adjustment induces the compression of the isopycnals that tend to stabilize the stratification on the sloping bathymetry. However, a secondary circulation between the epilimnion and the upper metalimnion (Fig. 6c) generates a supercritical shear layer that extends from the nearshore to the interior basin. The above flow patterns suggest that sloping topographies in stratified basins can foster strong heterogeneities in the flow stability.
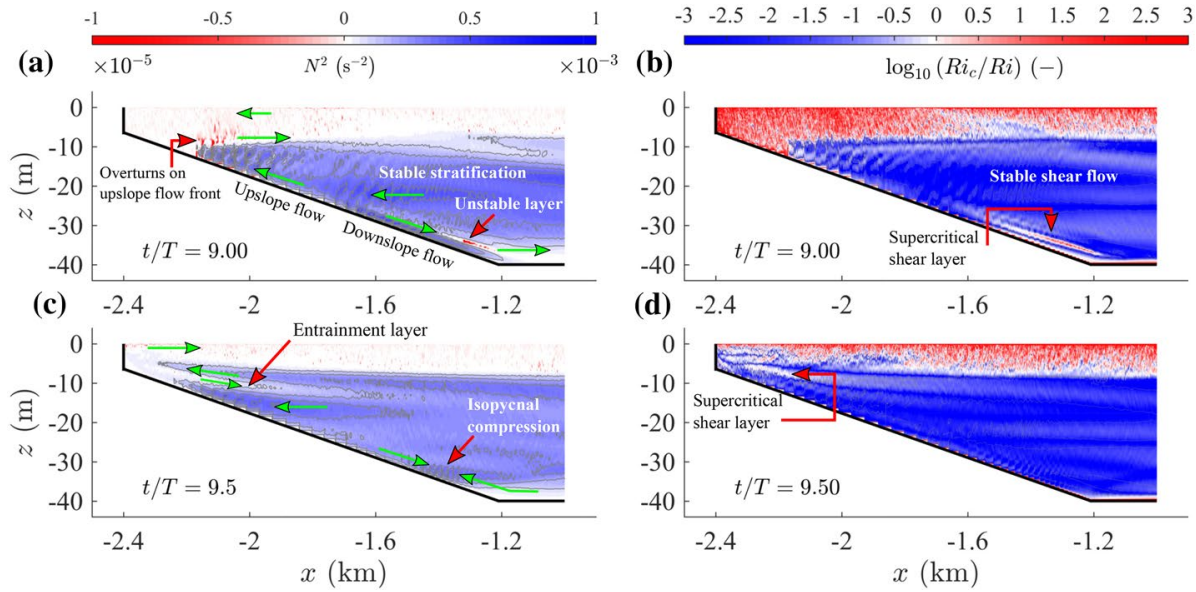

Fig. 6 Shear stability for the left slope region. a, c illustrate the fluid stability, $N^{2}=-\left(g / \rho_{1}\right) \partial \rho / \partial z$ and $\mathbf{b}, \mathbf{d}$ illustrate the shear stability parameter $\log _{10}\left(\mathrm{Ri}_{\mathrm{c}} / \mathrm{Ri}\right)$ at the start and at half of the wind-forcing cycle $(t / T=9.0 ; 9.5)$ on the left side of the domain. In the quasi-periodic flow regime, the second half of the forcing cycle has an antisymmetric response. Green arrows in the panels a, c schematize the flow propagation based on the circulation shown in Fig. 3, while red arrows stand out unstable density zones and supercritical shear flows 


\subsection{Bottom boundary layer flow}

We examine the structure of the BBL in two specific zones. Figure 7a and c show the Boussinesq density and the BBL flow pattern on the flat bottom zone, at $40 \mathrm{~m}$ depth and $2.4 \mathrm{~km}$ offshore (far from the inclined topography). Similarly, Fig. 7b and d show the Boussinesq density and the along-slope flow at $36 \mathrm{~m}$ depth and $\sim 1 \mathrm{~km}$ offshore, respectively. In both zones, the BBL flow shows a complex baroclinic signature, with significant vertical variability controlled by the local signature of the V2H1 basin-scale internal seiching. This variability is remarkably high on the sloping boundary due to the asymmetry in magnitude between the upslope and downslope currents. The above leads to substantial variations of the BBL thickness (see Fig. 7b). In particular, at the beginning of the wind-forcing phase (Fig. 7d), a keen downslope BBL current flows from mid-depths to the deepest basin. This current is balanced by a baroclinic upslope flow (above the BBL region) that transports hypolimnetic waters to metalimnetic depths. The downslope BBL current is bathymetrically driven to the flat bottom until reaching the center basin. Throughout this trajectory, the vertical profile of the BBL current changes drastically (compare panels $\mathrm{c}$ and d in Fig. 7).

Unlike the BBL flow on the sloping boundary, the BBL flow in the center of the basin shows a robust symmetry between positive and negative values over the wind-forcing cycle. Indeed, the flow shows a Stokes-boundary-layer-like pattern, resulting from the baroclinic streamwise pressure gradient, the unsteady acceleration, and the vertical momentum diffusion. The ratios between these three terms will depend on the strength of the stratification near the BBL and how close or far the flow is analyzed from the bottom boundary.

Here we investigate how well the law-of-the-wall logarithmic profile fits the model-predicted BBL flow. For this, we use a modified law-of-the-wall that incorporates the buoyancy effect in the near-bottom lateral flow $[64,71]$ :

$$
u_{b}=\frac{u_{\star}}{\kappa} \ln \left(\frac{D+z}{z_{0}}\right)+\frac{1}{C_{b}} \int_{-D}^{z} N(\tilde{z}) d \tilde{z},
$$

where $u_{\star}$ is the shear stress velocity, $\kappa=0.41$ is the von Kármán constant, $z_{0}$ is the hydrodynamic roughness, and $C_{b}$ is a constant that is set to be $C_{b}=1$ when a depth-dependent stratification, $N(z)$, is plugged in (7) [64]. Note that $u_{b}$ in (7) converges to the classic law-ofthe-wall [75] when $N(z) \rightarrow 0$. The fitting of $u_{b}$ to $u(z)$ (the numerical computed cross-shore flow) over the average BBL thickness, $h_{B B L}(x=0) \approx 2.3 \mathrm{~m}$ (grey shading in Fig. 7a, b), provides estimations of the friction parameters $u_{\star}$ and $z_{0}$. We use the squared correlation coefficient [4], $R^{2}$, as a metric to quantify the ability of expression (7) to describe the BBL flow profile.

Time series of $R^{2}, u_{\star}$ and $z_{0}$ are shown in Fig. 8a-c. A good fitting is arbitrary defined as $R_{\star}^{2} \geq 0.75$ (denoted by a green shading in Fig. $8 \mathrm{a}$ ). We found that in the deepest zone (redcircle marks in Fig. 8a) the modified law-of-the-wall fits roughly $56 \%$ of the wind-forcing cycle. In particular, high correlations are obtained during the wind strengthening phases, $t / T \in[9.0,9.25]$ and $t / T \in[9.5,9.75]$. The shear stress velocities, $u_{\star}$ (Fig. 8b), are found to be in the range of values estimated from field measurements in lakes, $u_{\star} \sim O\left(10^{-3}\right)$ $\mathrm{m} \mathrm{s}^{-1}[31,78]$. Yet, as the wind-forcing starts dropping $(t / T=9.25$ and $t / T=9.75)$, the hydrodynamic roughness, $z_{0}$ (Fig. 8c), becomes systematically larger than values reported in the literature, $z_{0} \sim O\left(10^{-3}-10^{-2}\right) \mathrm{m}[31,71,78]$. The last result is not rare. During the wind weakening phase, the BBL flow is more susceptible to be affected by baroclinic oscillations that can lead the flow to deviate from the modified logarithmic profile. These changes in the BBL flow structure are well illustrated in Fig. 7c. The velocity profiles at 
(a) $(x, y)_{\star}=(0,0) \mathrm{km}$

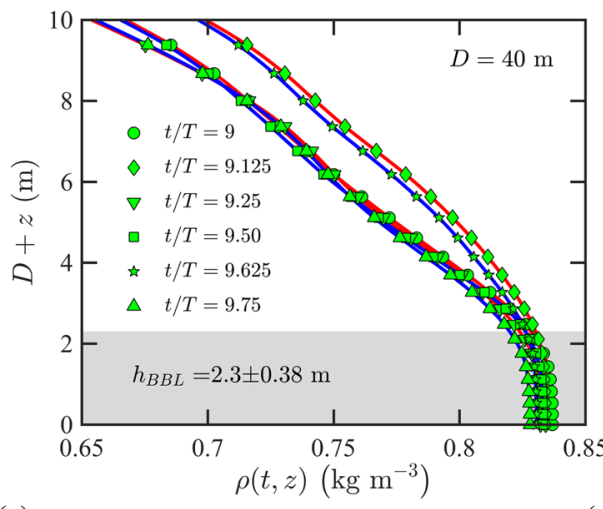

(c)

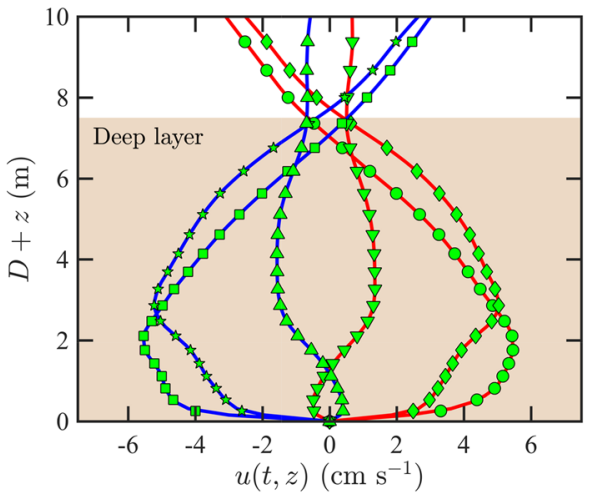

(b) $(x, y)_{\star}=(-1.35,0) \mathrm{km}$

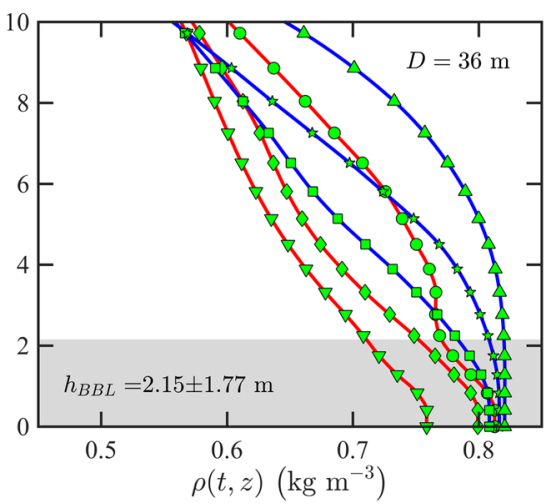

(d)

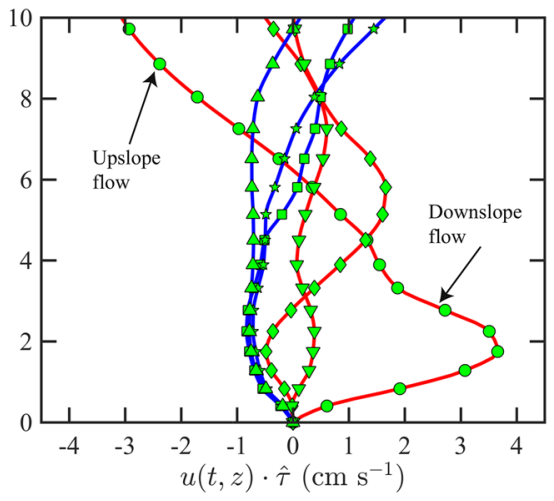

Fig. 7 Boundary layer dynamics: a, $\mathbf{c}(x, y) \approx(0,0) \mathrm{km}$ and $\mathbf{b}, \mathbf{d}(x, y) \approx(-1.35,0) \mathrm{km}$. Grey-shaded areas in a, b denote the BBL zone with $N^{2}<10^{-4} \mathrm{~s}^{-2}$. Time labelling is given in panel $\mathbf{a}$ and applies for panels $\mathbf{b}, \mathbf{c}$ and $\mathbf{d}$ as well. The flow and density structure during the first half of the diurnal phase is denoted by red lines while the second half is denoted by blue lines in all four panels

$t / T=9.25(\Delta$-line) and $t / T=9.75(\Delta$-line) show baroclinic signatures within the BBL (see Fig. 7a to identify the BBL zone).

To assess the sensibility of the modified law-of-the-wall profile to the fitting region, we fit Eq. (7) using the flow over half of the BBL, $h$ / 2 (blue stars in Fig. 8a-c). In this scenario, the fitting metric, $R^{2}$, increases substantially, reaching $88 \%$ over a cycle on the flat part of the $\mathrm{BBL}$. The fitting improvement is expected considering that flows closer to the bottom are less affected by unsteadiness and baroclinic perturbations that induce deviations from the law-ofthe-wall flow profile. Additionally, we estimate the percentage deviation between the friction parameters derived from Eq. (7) and the ones derived from the standard law-of-the-wall by setting $N=0$ in (7),

$$
e_{u_{\star}} \equiv 100 \times \frac{u_{\star}-u_{\star}(N=0)}{u_{\star}(N=0)}, \quad e_{z_{0}} \equiv 100 \times \frac{z_{0}-z_{0}(N=0)}{z_{0}(N=0)} .
$$

Figure $8 \mathrm{~d}$ and e show $\left|e_{u_{\star}}\right|$ and $\left|e_{z_{0}}\right|$, respectively, for $h_{B B L}=2.3 \mathrm{~m}$. We found that over most of the period, the percentage deviation of the friction parameters is less than $10 \%$. However, when wind-forcing starts dropping $(t / T=9.25$ and $t / T=9.75)$, the estimation of the friction parameters becomes remarkably sensitive to the fitting model, reaching 
(a) $\quad \cdots \cdots \cdots(x, y)_{\star}=(0,0) \mathrm{km}, D=40 \mathrm{~m}, h_{B B L}=2.33 \mathrm{~m} \cdots \cdots \cdots(x, y)_{\star}=(0,0) \mathrm{km}, D=40 \mathrm{~m}, h_{B B L} / 2$

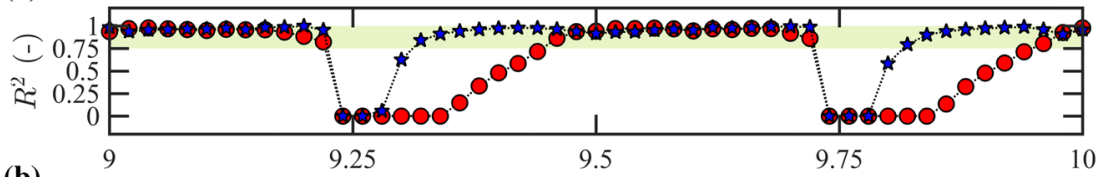

(b)

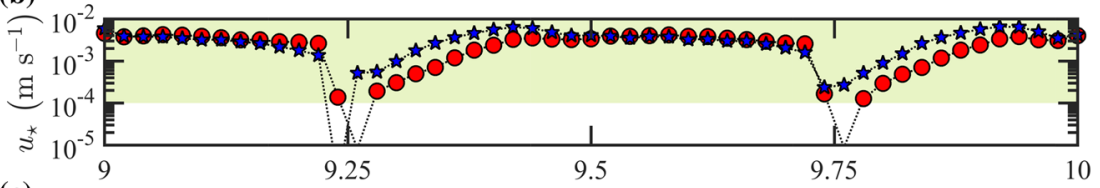

(c)
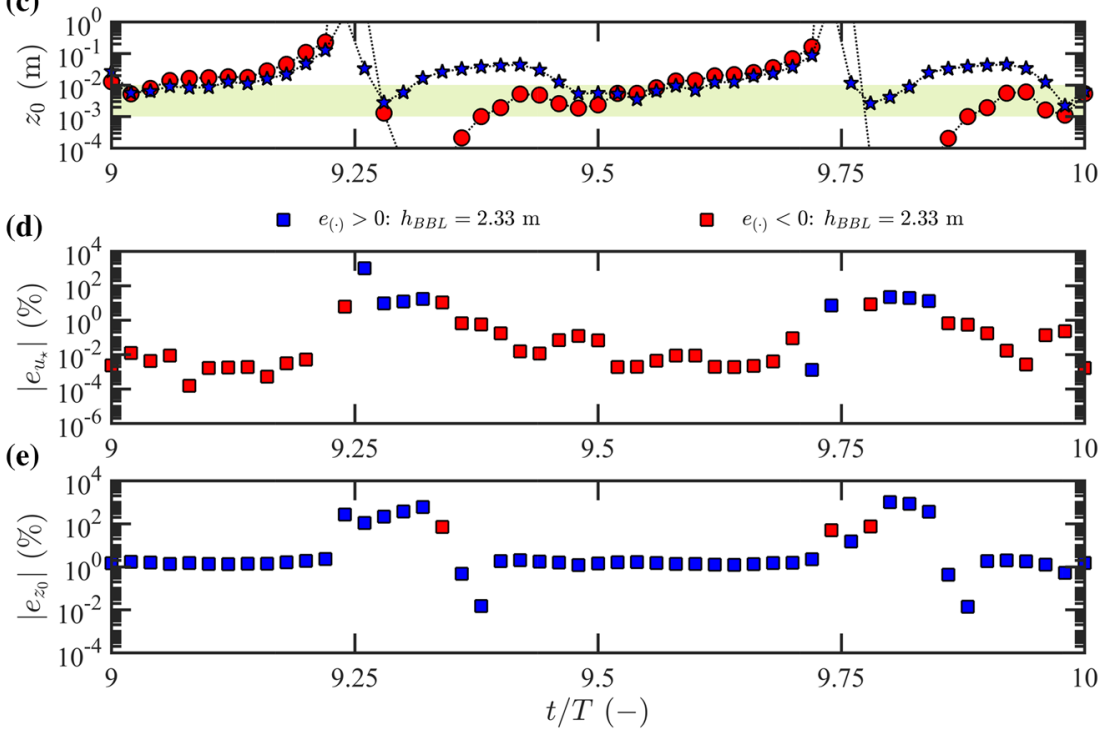

Fig. 8 Panels a-c show the square correlation coefficient, $R^{2}$, the bottom shear velocity, $u_{\star}$, and the bottom roughness, $z_{0}$, respectively, obtained by fitting a modified logarithmic law-of-the-wall profile (7) in the BBL. Green-shaded area in panel a highlights fittings with $R^{2} \geq 0.75$. Green-shaded area in panels $\mathbf{b}$, c denotes the observed range of shear velocity, $10^{-4} \leq u_{\star} \leq 10^{-2} \mathrm{~m} \mathrm{~s}^{-1}$, and bottom roughness, $10^{-3} \leq z_{0} \leq 10^{-2} \mathrm{~m}$, respectively, based on logarithmic profile fittings in stratified lakes [78]. Panels d and e show the perceptual difference between roughness parameters estimated from Eq. (7) and roughness parameters estimated from the classic law-of-the-wall BBL flow $(N=0)$ in center of the basin using $h_{B B L}=2.33 \mathrm{~m}: e_{u_{\star}} \equiv 100 \times\left[u_{\star}-u_{\star}(N=0)\right] / u_{\star}(N=0), e_{z_{0}} \equiv 100 \times\left[z_{0}-z_{0}(N=0)\right] / z_{0}(N=0)$. Blue squares denote $e_{(\cdot)}>0$ while red squares denote $e_{(\cdot)}<0$

discrepancies of up to $100 \%$. In contrast, no difference is obtained between the modified and the classic law-of-the wall for $h_{B B L}=2.3 / 2 \approx 1.2 \mathrm{~m}$. The above results indicate that friction parameters are strongly dependent on the flow unsteadiness and to a lesser extent on buoyancy effects.

The BBL structure has been recently investigated via field observation by Valipour et al. [71]. Their results showed that the logarithmic velocity profile is not a good predictor of the mixed layer thickness due to its sensitivity to the background seasonal stratification. Our numerical results are consistent with conclusions drawn from previous studies $[31,71]$ pointing out that the law-of-the-wall is not always a robust model for characterizing BBL flows unless the flow is steady and not affected by baroclinic flow motions. 


\section{Residual flow, cross-shore exchange, and flushing timescale}

We investigate the residual cross-shore flow circulation resulting over a full wind-forcing period. For this, we compute the spanwise- and time-average over a full forcing period $T$, $\langle\cdot\rangle_{s w, T}$, of the velocity and density fields, $u_{r} \equiv\langle u\rangle_{s w, T}$ and $\rho_{r} \equiv\langle\rho\rangle_{s w, T}$, respectively. Figure 9a shows the density distribution, $\rho_{r}$, overlaid by isopycnals (grey-lines) which are found slightly more elevated in the nearshore zone (sloping boundaries) than in the interior. The residual density map suggests the existence of an upslope net flux that deviates the isopycnals from their horizontal position, especially in upper metalimnetic zones. This density distribution, in turn, sets up a cross-shore density gradient that should be balanced by a buoyancy-driven cross-shore flow. The residual streamwise velocity pattern, $u_{r}$ (along with the residual streamlines), shown in Fig. $9 \mathrm{~b}$ is consistent with the flow circulation expected from the residual density distribution, $\rho_{r}$. Although the residual flow is weak, $u_{r} \sim O\left(10^{-3}\right) \mathrm{m} \mathrm{s}^{-1}$, its vertical structure is compounded by multiple cells that enhance the cross-shore circulation along the sloping boundaries. In particular, the strongest cross-shore circulation cell correlates with the largest isopycnal deviation, in the nearshore upper metalimnion zone. This cell spans from shallow nearshore zones to mid-depths at the center of the basin. Here, we quantify the crossshore mass exchange based on both the instantaneous and the residual fields (Figs. 3 and 9).

We examine the cross-shore exchange as a function of time and the cross-shore $x$-axis via two different quantities. First, we study the dimensionless 'Rate of Mass Exchange' at the diurnal scale, $R_{e x}$, driven by the cross-shore flow component, $u$,

$$
R_{e x}\left(t_{*}, x_{*}\right) \equiv \frac{M_{e x}\left(t_{*}, x_{*}\right)}{M\left(t_{*}, x_{*}\right)},
$$

where $M_{e x}\left(t_{*}, x_{*}\right)$ is the spanwise-average integrated mass exchange at a specific offshore distance, $x_{*}$, at time $t_{*}$,

$$
M_{e x}\left(t_{*}, x_{*}\right)=\int_{t_{0}}^{t_{*} \leq T} F_{e x}\left(t, x_{*}\right) d t,
$$

where

$$
F_{e x}\left(t_{*}, x_{*}\right)=\frac{1}{2} \int_{D\left(x_{*}\right)}^{0}\left|\langle\rho(t, \mathbf{x}) u(t, \mathbf{x})\rangle_{s w}\right| d z,
$$

is the cross-shore mass flux through the full water column at a distance $x_{*}$ from the left shore, and time $t_{*} \leq T$. The spanwise-averaged mass contained in the wedge-like shore volume at a distance $x_{*}$ and at time $t_{*}$ is:

$$
M\left(t_{*}, x_{*}\right)=\int_{D\left(x_{*}\right)}^{0} \int_{0}^{x_{*}}\left\langle\rho\left(t_{*}, \mathbf{x}\right)\right\rangle_{s w} d x d z .
$$

Thus, $R_{e x}$ provides information on the renewed mass as a function of time at a certain distance from the shore. Additionally, $R_{e x}$ allows finding regions that are fully flushed due to the cross-shore transport by solving $R_{e x}\left(t_{*}, x_{*}\right)=1$. 

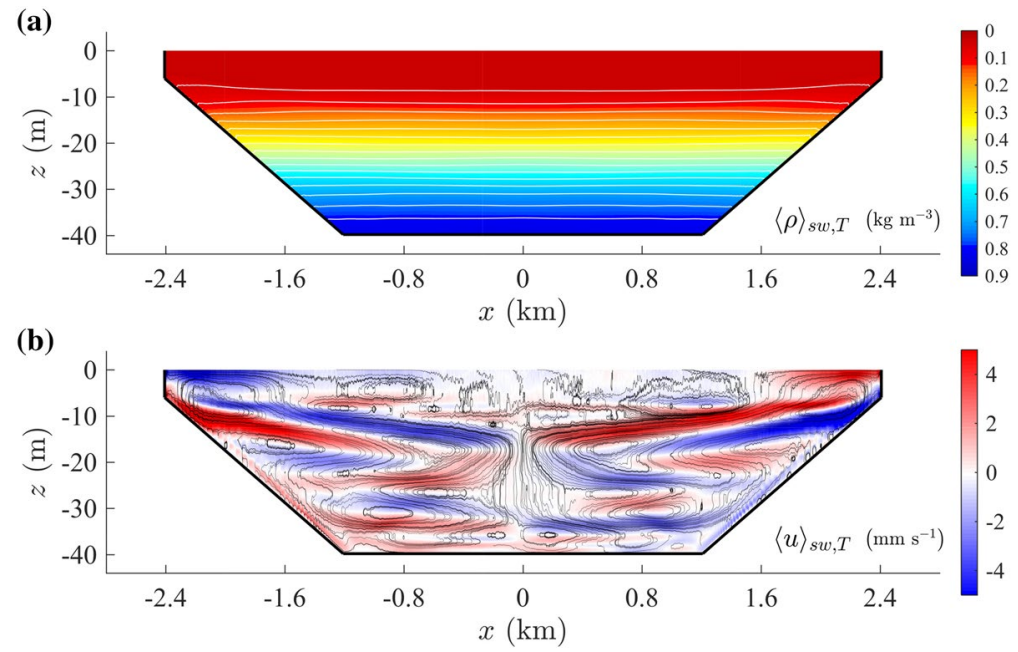

Fig. 9 Residual flow. a Spanwise- and time-averaged Boussinesq density, $\langle\rho\rangle_{s w, T}$, overlaid by isopycnals (grey lines). b Spanwise- and time-averaged streamwise flow, $\langle u\rangle_{s w, T}$, overlaid by spanwise- and time-averaged streamlines

Second, we study the cross-shore mass exchange and the flushing timescale based on the residual fields, $u_{r}$ and $\rho_{r}$,

$$
T_{F}\left(t_{*}, x_{*}\right) \equiv \frac{M\left(t_{*}, x_{*}\right)}{F_{e x}\left(t_{*}, x_{*}\right)},
$$

where $M\left(t_{*}, x_{*}\right)$ and $F_{e x}\left(t_{*}, x_{*}\right)$ correspond to the mass (12) and the cross-shore mass flux (11) computed from the residual fields (Fig. 9). Figure 10a maps $R_{e x}$ as a function of $x$ and the diurnal time, overlaid by blue lines that denote different rates of the total mass integrated at $\left(t_{*}, x_{*}\right)$, and $R_{e x}\left(t_{*}, x_{*}\right)=1$ defines the region where $100 \%$ of the contained mass has been exchanged during the diurnal phase. The wind-driven flow and the resulting baroclinic circulation can completely exchange the nearshore water $\sim 0.2 \mathrm{~km}$ from the shore, at half a period $(12 \mathrm{~h}$ ), and even $\sim 0.6 \mathrm{~km}$ offshore at the end of the full period.

The flushing timescale computed from the residual fields and normalized by the fundamental basin-scale timescale, $T_{V 2 H 1}=24 \mathrm{~h}$, is shown in Fig. $10 \mathrm{~b}$ as a function of the cross-shore axis $x$ (normalized by $L_{x} / 2=1.2 \mathrm{~km}$ ). We obtain that the residual flow can completely flush the nearshore zone $(\sim 0.2 \mathrm{~km})$ at the end of the first day, and the full sloped basin $(\sim 1.2 \mathrm{~km})$ roughly after 13 days. These results indicate that the winddriven cross-shore circulation and its residual flow can renew nearshore waters at the diurnal scale. Notice that the strength of the cross-shore mass exchange and the flushing timescale will depend directly on the wind-driven surface shear stress, $\tau_{0}$, and the crossshore bed-slope, $\tan (\beta)$. In particular, we stress that the cross-shore exchange is affected by the background stratification and the basin topography $\left(D, L_{x}\right)$. The above parameters control the structure of internal oscillations and resulting baroclinic flows. 


\section{Energy distribution}

In this section, we illustrate the spatio-temporal distribution of relevant energetics to characterize the intensity of turbulence and mixing in the periodically wind-forced stratified basin.

\subsection{Spanwise/time-averaged quantities}

The energy distribution is examined via the kinetic energy per unit mass, $K E=\mathbf{v}^{2} / 2$, the vertical buoyancy flux, $b=\left(g / \rho_{1}\right)\left[\left\langle\rho^{\prime} w^{\prime}\right\rangle+\kappa_{s g s} \partial_{z} \rho\right]$, the $K E$ dissipation rate $\varepsilon=2 \nu S_{i j}^{2}+2 v_{s g s} S_{i j}^{2}$ where $S_{i j}$ is the strain-rate tensor, and the effective eddy diffusivity estimated as $K_{\rho}=-b / N^{2}[44,46,58]$. We note that the subgrid-scale diffusivity $\kappa_{s g s}$ in the instantaneous flow field ranges from its molecular value $\kappa$ to approximately $20 \kappa$. Figure 11 illustrates the spanwise- and time-averaged values of the above fields. The results show that $\langle K E\rangle_{s w, T}$ (Fig. 11a), $\langle b\rangle_{s w, T}$ (Fig. 11b), $\langle\varepsilon\rangle_{s w, T}$ (Fig. 11c) and $\left\langle K_{\rho}\right\rangle_{s w, T}$ (Fig. 11d) reach the highest magnitudes in the epilimnion. In contrast, the magnitudes of these quantities are drastically diminished in the metalimnion and hypolimnion. Also, the above quantities exhibit a significant along-slope variability between 10 and $20 \mathrm{~m}$ depth, reaching minimum values between 20 to $30 \mathrm{~m}$ depth, and showing a local amplification between 30 to $35 \mathrm{~m}$ depth. This local amplification is correlated with the location of supercritical shear layers driven by upslope/downslope BBL currents (Fig. 6). Besides the along-slope variability, the spatial distribution of $\langle K E\rangle_{s w, T},\langle b\rangle_{s w, T},\langle\varepsilon\rangle_{s w, T}$ and $\left\langle K_{\rho}\right\rangle_{s w, T}$ is characterized by a layered structure.

Figure 11c shows $\langle\varepsilon\rangle_{s w, T}$. The minimum values of $\langle\varepsilon\rangle_{s w, T}$ are found in the interior basin, with magnitudes of $\langle\varepsilon\rangle_{s w, T} \approx 10^{-11} \mathrm{~W} \mathrm{~kg}^{-1}$, while maximum values are found in the surface, with magnitudes $\langle\varepsilon\rangle_{s w, T} \approx 10^{-7} \mathrm{~W} \mathrm{~kg}^{-1}$. In the BBL, the values range $10^{-9} \leq\langle\varepsilon\rangle_{s w, T} \leq 10^{-8} \mathrm{~W} \mathrm{~kg}^{-1}$ over the flat boundary, and $10^{-10} \leq\langle\varepsilon\rangle_{s w, T} \leq 10^{-9} \mathrm{~W} \mathrm{~kg}^{-1}$

(a)

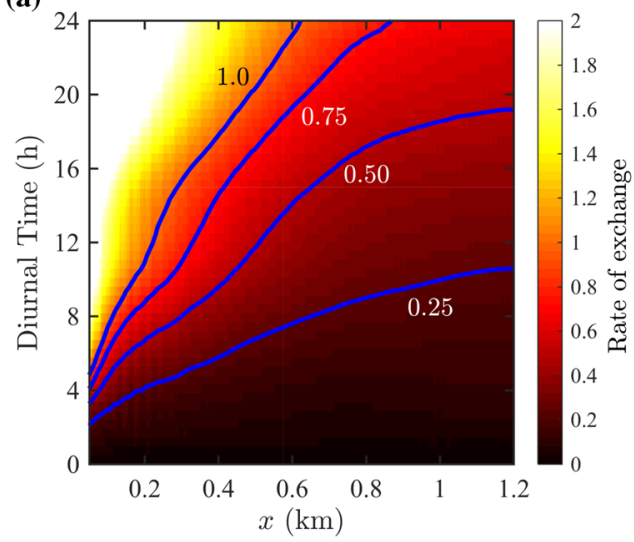

(b)

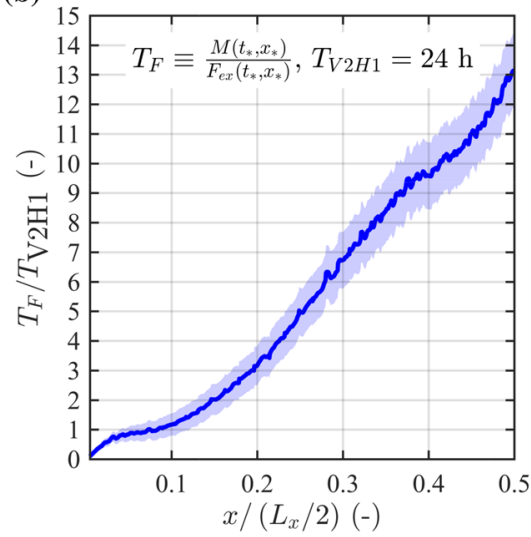

Fig. 10 Cross-shore mass exchange. a Rate of mass exchange, $R_{e x}$, between nearshore and offshore region, $0 \leq x \leq 1.2 \mathrm{~km}$, during one diurnal period, $0 \leq t \leq 24 \mathrm{~h}$; blue lines show four specific $R_{e x}(25 \%, 50 \%, 75 \%$, and $100 \%)$ from the left-boundary to a specific distance $x$ as a function of time. $\mathbf{b}$ Normalized flushing timescale $T_{F} / T_{V 2 H 1}$ of nearshore regions $0 \leq x /\left(L_{x} / 2\right) \leq 0.5$, with $T_{V 2 H 1}=24 \mathrm{~h}$ and $L_{x}=2.4 \mathrm{~km}$, based on the residual cross-shore mass transport (see Fig. 9) 
over the inclined boundary. The drop of $\langle\varepsilon\rangle_{s w, T}$ in the sloping BBL can be associated with the stabilizing effect that stratification exerts on the along-slope flows. Overall, the results show that the magnitudes of $\langle\varepsilon\rangle_{s w, T}$ are inversely proportional to the fluid stability, $N^{2}$, and proportional to $\left\langle K_{\rho}\right\rangle_{s w, T}$, shown in Fig. 11d. The green contour line in Fig. 11d denotes the molecular zone, where $\left\langle K_{\rho}\right\rangle_{s w, T} \approx O(\kappa)$ ( $\kappa$ the molecular thermal diffusivity). This zone is extended over most of the interior basin, roughly from 20 to $35 \mathrm{~m}$ depth. In the epilimnion, by contrast, $\left\langle K_{\rho}\right\rangle_{s w, T}$ is almost four orders of magnitude larger than the molecular diffusivity, $\left\langle K_{\rho}\right\rangle_{s w, T} \approx 10^{-3} \mathrm{~m}^{2} \mathrm{~s}^{-1}$, whereas in the BBL of the flat bottom it ranges $10^{-5} \leq\left\langle K_{\rho}\right\rangle_{s w, T} \leq 10^{-4} \mathrm{~m}^{2} \mathrm{~s}^{-1}$. Similar to $\langle\varepsilon\rangle_{s w, T}$, the most significant lateral varibility of $\left\langle K_{\rho}\right\rangle_{s w, T}$ is found in the upper metalimnion, between 10 to $15 \mathrm{~m}$ depth. In this region, $\left\langle K_{\rho}\right\rangle_{s w, T}$ drops almost two orders of magnitude from the BBL towards the interior.

\subsection{Horizontally-averaged quantities as a function of time and depth}

The horizontally-averaged energy dissipation rate, $\langle\varepsilon\rangle_{H}$ (Fig. 12a), shows variations of about two orders of magnitude in the epilimnion over the diurnal cycle; $\langle\varepsilon\rangle_{H}$ reaches minimum $\left(\sim 10^{-9} \mathrm{~W} \mathrm{~kg}^{-1}\right.$ at $2 \mathrm{~h}$ and $\left.14 \mathrm{~h}\right)$ and maximum $\left(\sim 10^{-7} \mathrm{~W} \mathrm{~kg}^{-1}\right.$ at $8 \mathrm{~h}$ and $\left.20 \mathrm{~h}\right)$ magnitudes. These extreme values are observed $2 \mathrm{~h}$ after the respective minimum and maximum, respectively, of the wind shear stress over the diurnal cycle. The values of $\langle\varepsilon\rangle_{H}$ within the deep layer also show two orders of magnitude of diurnal variability, reaching minimum and maximum values approximately at $12 \mathrm{~h}$ and $24 \mathrm{~h}$ as well as $8 \mathrm{~h}$ and $20 \mathrm{~h}$, respectively. Despite the diurnal variability, the laterally- and time-averaged profile of $\varepsilon$ (blue line in Fig. 12b) shows significant similarity in terms of the magnitudes and the vertical distribution observed by Wüest et al. [79] in Lake Alpnach. Indeed, Wüest et al. [79] reported maximum values near the surface, $\langle\varepsilon\rangle_{H, T} \approx 10^{-7} \mathrm{~W} \mathrm{~kg}^{-1}$, minimum values at $\approx 20 \mathrm{~m}$ depth, $\langle\varepsilon\rangle_{H, T} \approx 10^{-11}-10^{-10} \mathrm{~W} \mathrm{~kg}^{-1}$, and values of $\langle\varepsilon\rangle_{H, T} \approx 10^{-8} \mathrm{~W} \mathrm{~kg}^{-1}$ near the flat BBL, as shown in Fig. 14c. In contrast, the time-averaged profile at the center of the basin (green line) has lower values in the interior of the basin, especially for depths between $10 \mathrm{~m}$ and $30 \mathrm{~m}$; this result highlights the role of lateral boundaries as dissipative zones.

Similarly, $\langle b\rangle_{H}$ (Fig. 12e) also shows two orders of magnitude variability in the surface and deepest zones, with the same diurnal modulation of $\langle\varepsilon\rangle_{H}$. The background buoyancy flux (red-line in Fig. 12f) is characterized by two peaks, the largest occurring at $6 \mathrm{~m}$ depth, $\langle b\rangle_{H} \approx 2 \times 10^{-9} \mathrm{~W} \mathrm{~kg}^{-1}$, and the second largest at $35 \mathrm{~m}$ depth, $\langle b\rangle_{H} \approx 10^{-9} \mathrm{~W} \mathrm{~kg}^{-1}$. If we do not include the bottom boundary, the minimum values of $\langle b\rangle_{H}$ are found between 15 to $35 \mathrm{~m}$ depth, where $\langle b\rangle_{H} \approx 2.5 \times 10^{-10} \mathrm{~W} \mathrm{~kg}^{-1}$. We also observe that $\left\langle K_{\rho}\right\rangle_{H}$ (Fig. 12g) is in phase with $\langle\varepsilon\rangle_{H}$ (compare time series of panels a and g in Fig. 12). $\left\langle K_{\rho}\right\rangle_{H}$ has a substantial diurnal variability at depths of about $10 \mathrm{~m}$ and close to the BBL, changing by two orders of magnitude every $6 \mathrm{~h}$. Figure $12 \mathrm{~h}$ illustrates the lateral- and time-averaged vertical diffusivity, $\left\langle K_{\rho}\right\rangle_{H, T}$ (blue line), which shows reasonable agreement with the vertical diffusion estimated from field measurements by Gloor et al. [19] in Lake Alpnach (see Fig. 14d). Yet, in the case of $\left\langle K_{\rho}\right\rangle_{H, T}$, field-based estimations are limited to the hypolimnion (interior) and deep regions (near the BBL) (Fig. 14d). In these zones, the numerical results predict magnitudes of $K_{\rho} \approx 10^{-6} \mathrm{~m}^{2} \mathrm{~s}^{-1}$ in the hypolimnion and up to $K_{\rho} \approx 10^{-5}-10^{-4} \mathrm{~m}^{2} \mathrm{~s}^{-1}$ near the bottom (Fig. 12h). Likewise, the field-based estimations of $K_{\rho}$ show magnitudes of $K_{\rho} \approx 10^{-6} \mathrm{~m}^{2} \mathrm{~s}^{-1}$ at hypolimnetic depths and $K_{\rho} \approx 10^{-5} \mathrm{~m}^{2} \mathrm{~s}^{-1}$ near the bottom (Fig. 14d). 


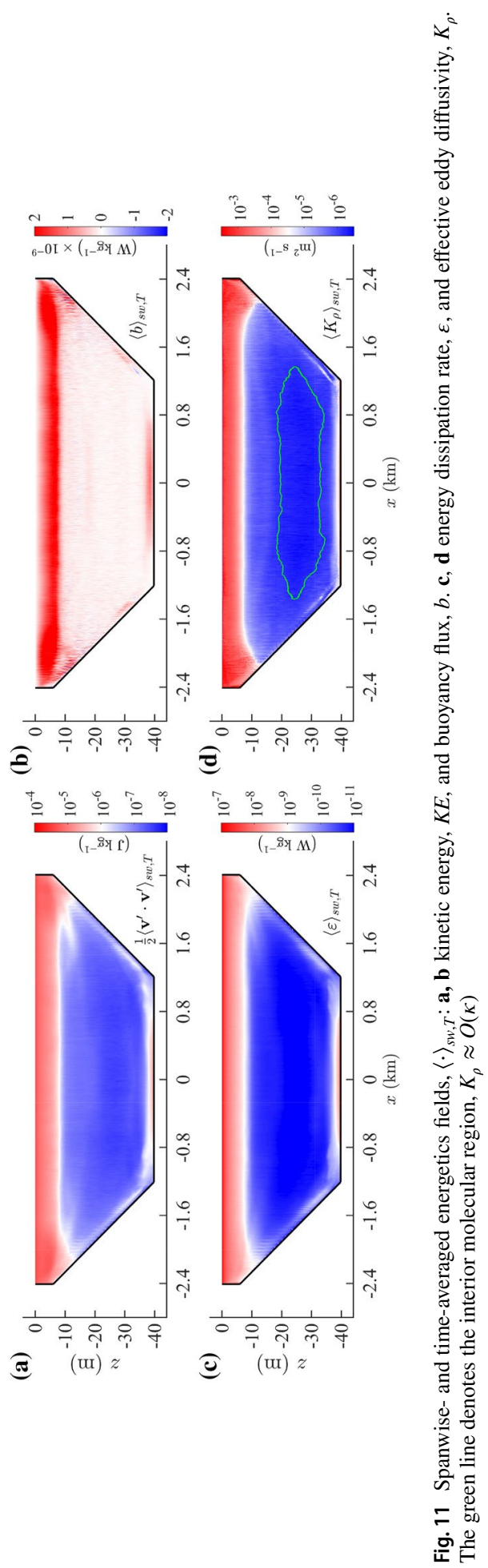



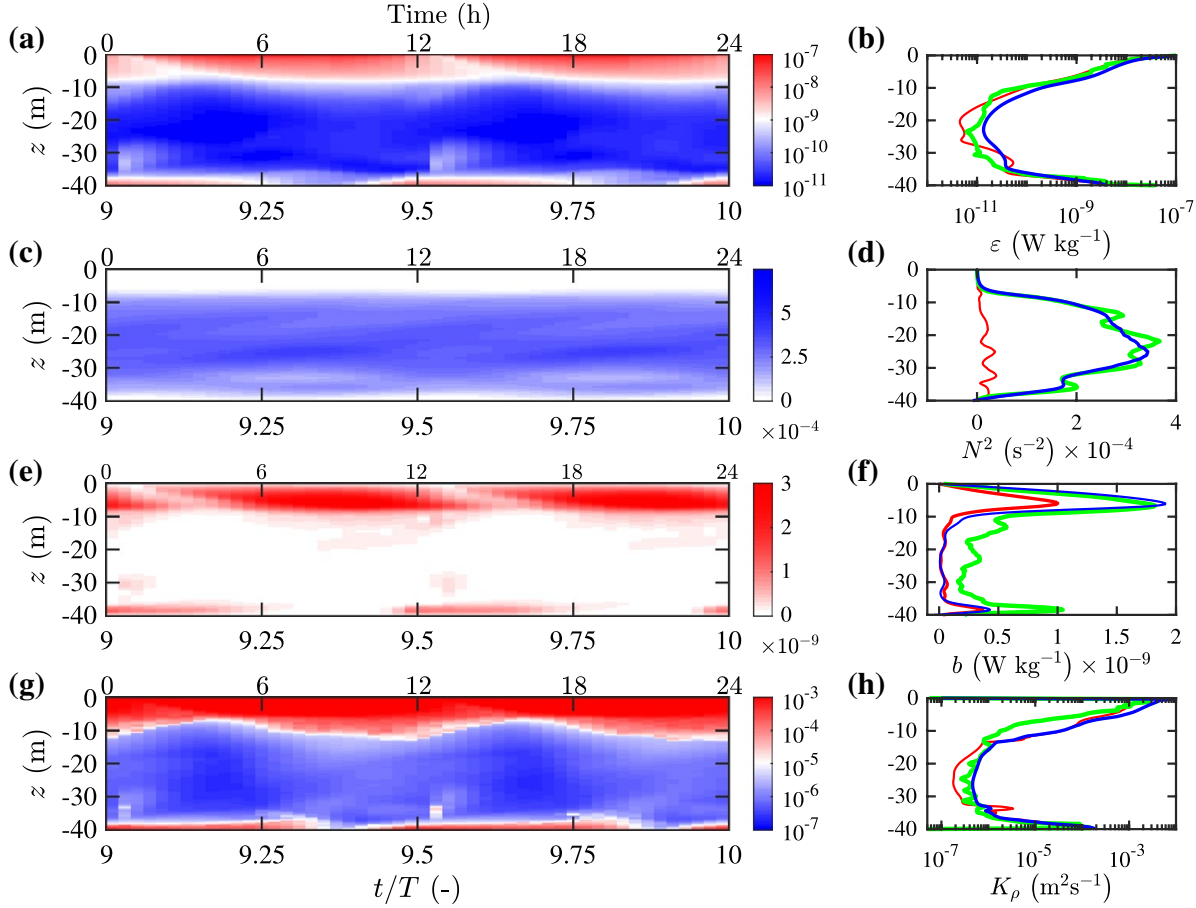

Fig. 12 Diurnal evolution of the laterally-averaged vertical profiles of $\mathbf{a}$, b energy dissipation rate, $\langle\varepsilon\rangle_{H}$, c, d fluid stability, $\left\langle N^{2}\right\rangle_{H}$. e, f vertical buoyancy flux, $\langle b\rangle_{H}$, and $\mathbf{g}$, h vertical eddy diffusivity, $\left\langle K_{\rho}\right\rangle_{H}$, along with their respective laterally- and time-averaged vertical profiles (blue lines), their standard deviation (red line), and the time-averaged vertical profile at the center of the basin $(x, y)=(0,0)$ (green line). The vertical structure of the afore-mentioned quantities shows significant variability over the wind-forcing cycle in the epilimnion and hypolimnion layers, but negligible changes in the metalimnion

\subsection{Bulk energetic regimes}

We investigate the bulk energetic regimes via the turbulence intensity parameter and the dimensionless effective diffusivity,

$$
\mathcal{I} \equiv \frac{\varepsilon}{v N^{2}}, \quad \mathcal{K} \equiv \frac{K_{\rho}+\kappa}{\kappa},
$$

respectively $[8,27,58] . \mathcal{I}$ is also known as the buoyancy Reynolds number that characterizes the strength of turbulence subjected to the stabilizing effect of stratification. We computed spatial averages of $\mathcal{I}$ and $\mathcal{K}$ to examine their bulk magnitudes and diurnal evolution in five relevant zones: (1) the epilimnion (EPI), (2) the metalimnion (MET), (3) the hypolimnion (HYP), (4) the Slope BBL (SBBL) and (5) the BBL region situated in the deep flat part of the bottom boundary. We further estimate the ratio

$$
\Gamma=\frac{1}{\operatorname{Pr}} \frac{\langle\mathcal{K}\rangle}{\langle\mathcal{I}\rangle},
$$


(a)

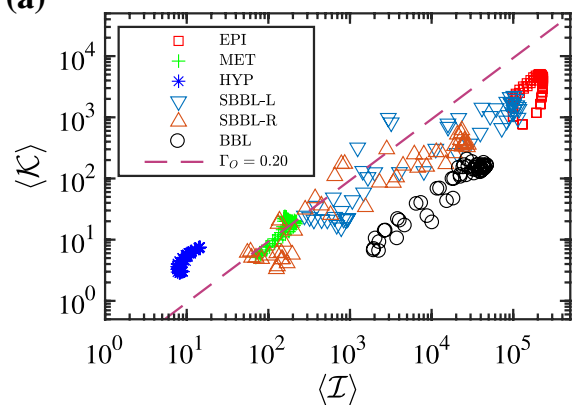

(b)

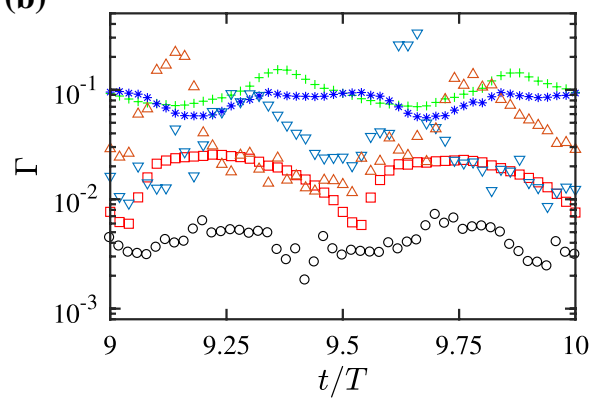

Fig. 13 a Turbulence and mixing regime diagram: dimensionless eddy diffusivity, $\mathcal{K}$, as a function of the turbulence intensity, $\mathcal{I}$, for each zone over the diurnal phase; dash-line denotes the Osborn's constant mixing efficiency, $\Gamma_{O}=0.2$. Zones are defined as a function of depth, $z$, the streamwise axis, $x$, and the height, $h$, measured from bottom upward: (1) EPI: $z \in[-6,0] \mathrm{m}$ (red-square); (2) MET: $z \in[-20,-6] \mathrm{m}$ (green-cross), $x \in[-1.2,1.2] \mathrm{km}$; HYP: $z \in[-36,-20] \mathrm{m}, x \in[-1.0,1.0] \mathrm{km}$ (blue-asterisk); (4) SBBL: $h \in[0,4] \mathrm{m}, x \in[-2.4,-1.2] \mathrm{km}$ (Left slope: orange triangle) and $h \in[0,4] \mathrm{m}, x \in[1.2,2.4] \mathrm{km}$ (right slope: blue triangle); (5) BBL: $h \in[0,4] \mathrm{m}, x \in[-1.2,1.2] \mathrm{km}$ (black-circle). b Diurnal variability of $\Gamma=\operatorname{Pr}^{-1}\langle\mathcal{K}\rangle /\langle\mathcal{I}\rangle$ at each zone

which can be considered as a bulk mixing efficiency of a specific volume [46]. Here the angle brackets indicate spatial average over the relevant zones. The turbulence intensity parameters are mapped in the $\mathcal{I}-\mathcal{K}$ plane along with the Osborn's constant mixing efficiency, $\Gamma_{O}=0.2$, as a reference in Fig. 13a. The highest values of $\mathcal{I}$ and $\mathcal{K}$ are found in the EPI, where they reach values of $\langle\mathcal{I}\rangle_{E P I} \approx 10^{5}$ and $\langle\mathcal{K}\rangle_{E P I} \approx 10^{3}-10^{4}$. In this zone, $\Gamma_{E P I}$ ranges from $10^{-3}$ to $10^{-2}$ (see red square marks in Fig. $13 \mathrm{a}$ and b respectively). In contrast, the maximum values for $\mathcal{I}$ and $\mathcal{K}$ in the MET are $\langle\mathcal{I}\rangle_{M E T} \approx 10^{2}$ and $\langle\mathcal{K}\rangle_{M E T} \approx 10^{1}$, respectively, whereas $\Gamma_{M E T} \approx 10^{-1}$ (see green cross marks in Fig. 13a and b, respectively). The lowest variability as well as the lowest bulk mixing rate was found in the BBL zone (flat bottom boundary), with $\Gamma_{B B L} \approx 10^{-3}$. However, the numerical results indicate that the turbulence intensity and bulk mixing efficiency are highly variable inside the slope boundary layer zones (SBBL). In these regions, the background stratification is interacting with strong back-and-forth along-the-slope currents (stirring) controlled by the basin-scale internal seiching [33] that enhances the local shear and the buoyancy flux (see up-looking and down-looking triangles in Fig. 13). In the SBBL, the bulk mixing efficiency reaches a value of $\max \left(\Gamma_{S B B L}\right) \approx 0.35$.

\section{Discussion}

Adopting the physical scales of Lake Alpnach (Switzerland) for typical stratification and wind conditions observed during the summer seasons, a 3-D LES was performed to examine the basin-scale hydrodynamics in a wind-forced, small and narrow stratified basin. Despite the simplified geometry, the numerical experiment reproduces the primary physical processes observed in Lake Alpnach, such as the basin-scale modal response, BBL currents, and the general circulation. Additionally, the simulation allowed characterizing the residual basin-scale circulation, quantifying the wind-driven baroclinic cross-shore mass 
exchange and exploring the spatio-temporal distribution of energy, turbulence intensity and mixing rate at diurnal scale.

Basin-scale circulation We found that the quasi-resonance regime between diurnal wind-forcing and the V2H1 internal seiche controls the basin-scale circulation pattern, including BBL currents. In the case of the sloping boundary regions, the mid-layer lateral transport, resulting from the $\mathrm{V} 2 \mathrm{H} 1$ modal response, forces divergent and convergent alongslope boundary currents that periodically squeeze and stretch the metalimnetic isopycnals in nearshore waters. Moreover, we remark the emergence of supercritical shear layers and density overturns along the inclined bottom, especially in the upper and lower metalimnion associated with both upslope and downslope flows, respectively. This along-slope dynamics partially differs from the results obtained by Becherer and Umlauf [3], who found that downslope BBL currents are a stabilizing mechanism of the local stratification.

There are at least four factors that might lead to systematic differences between the results reported by Becherer and Umlauf [3] and ours regarding the along-slope BBL flow: (i) Our numerical experiment does not include Coriolis acceleration which can affect the up- and downslope flow symmetry especially in nearshore regions where along-shore flows drive cross-shore Ekman transport; (ii) unlike to the numerical framework used by Becherer and Umlauf [3], our numerical experiment is fully non-hydrostatic and has a higher horizontal resolution allowing to solve strong along-slope flow propagations; (iii) Becherer and Umlauf [3] employed a general vertical coordinate scheme to refine the resolution along the BBL allowing higher resolution at mid-depths than our model; and (iv) the geometrical symmetry of our stratified basin can lead to more symmetric upslope and downslope flows, which is not necessarily the case for realistic and complex bathymetry such as the one used by Becherer and Umlauf [3]. Despite the above differences, our idealized experiment reproduces the main basin-scale processes found both in field observations $[32,41]$ and in a RANS numerical experiment performed in a more realistic geometry [3].

The linear normal modes on complex stratified basins can be investigated by solving the 2-D (or 3-D) eigenvalue problem [18, 34, 73]. This type of analysis might allows examining the modal response of the flow along sloping boundaries and thus identifying regions where local bathymetric conditions might potentially intensify BBL currents.

Cross-shore exchange Based on the diurnal cross-shore flow component, we computed the rate of exchange between nearshore and offshore waters as a function of the cross-shore axis and time. Our main finding is that $100 \%$ of the water stored in the nearshore zone, in particular from the shore to $0.5 \mathrm{~km}$ offshore, can be exchanged over a one-day cycle by the wind-driven flow. Also, from the quasi-steady residual flow $\left(\sim 2 \mathrm{~mm} \mathrm{~s}^{-1}\right)$, we estimate that the residual cross-shore transport can flush the first $200 \mathrm{~m}$ from the shore in one day, and $1 \mathrm{~km}$ from the shore in ten days. Performing this analysis with higher resolution would lead to more robust estimations, and even higher exchange rates since the contribution of smaller length scales would be included in the net transport.

Overall, the rate of exchange and flushing timescale of nearshore zones will depend on the cross-shore bed-slope, the wind strength, and the natural modal response of the stratified basin. These results cannot be directly generalized to other lakes yet quantifying the cross-shore exchange process is relevant for the transport of biogeochemical constituents [40]. For instance, the rate of exchange and flushing timescale obtained show reasonable magnitudes compared to the horizontal transport observed by Wain et al. [76] in Lake West Okoboji, Iowa, and by Goudsmit et al. [20] in Lake Alpnach. Note finally that a global investigation of the cross-shore water exchange shall include other processes such as thermally-driven buoyancy flows $[17,39,70]$. 
Turbulence intensity The vertical signatures of the energy dissipation rate, $\varepsilon$, estimated from the numerical experiment, showed good agreement in terms of the overall magnitude levels and vertical distribution with the available observations in Lake Alpnach [79] and other similar stratified basins $[60,76]$. The highest turbulence intensity was found in the surface mixed layer, while the interior (hypolimnion) layer, the turbulence intensity was fairly weak and the effective eddy diffusivity was close to the molecular value $K_{\rho} \approx \kappa$. The most significant diurnal variability of the turbulence intensity parameters $\mathcal{I}$ and $\mathcal{K}$, and of the bulk mixing efficiency, $\Gamma$, was observed in the upper metalimnion and over the slope boundaries zones. These regions are actively energized by the dominant V2H1 internal seiche that induces strong along-the-slope currents in a zone that is affected by the most robust fluid stability $N^{2}$. Similarly to the turbulent mixing observed near submarine topographies [36, 77], we found that the stratified slope boundaries regions are hot spots for strong mixing episodes.

Based on the mixing regime classification $[8,27,58]$, our estimation of the mixing efficiency inside the slope boundary regions can vary from transitional to energetic regimes $10^{1} \leq \mathcal{I} \leq 10^{4}$. The maximum mixing efficiency values, $\Gamma \approx 0.35$, are attributed to transitional mixing regimes, where the turbulence intensity parameter reached $\mathcal{I} \approx 10^{1}-10^{2}$. In contrast, the almost quiescent hypolimetic zone was found to be in the buoyancy-controlled energetic regime proposed by Bouffard and Boegman [8], $10^{0}<\mathcal{I}<10^{1}$ (molecular regime for Shih et al. [58] and Ivey et al. [27]). Note that in our shallow system, the hypolimnetic zone does not escape completely from the stabilizing effect of the background stratification. Indeed, the weak stratification even in the deep regions is robust enough to stabilize the shear flows induced by the V2H1 internal seiche.

Although observations and the model show that stable vertical shear flows characterize interior zones, boundary zones at mid-depths are expected to be periodically subject to strong stratified shear flows able to generate turbulent patches that would require vertical resolutions of millimetres. Solving this type of process in stratified lakes poses a real challenge for numerical modeling and will require further studies. Still, despite the constraint established by the vertical resolution, the model reproduces reasonably well the observed vertical signature of the energetic quantities examined. Our results illustrate the strategic role played by numerical experiments for expanding the exploration of physical processes that matter to quantify transport and mixing in aquatic systems. We expect that numerical experiments with more extended time series and higher spatial resolutions will allow quantifying more robustly the relevance of turbulent fluxes and the overall hydrodynamic transport in stratified lakes.

The benefits of using LES instead of RANS are numerous, especially for small lakes for which todays computing resources allow performing such eddy resolving simulations [56]. LES is more accurate than RANS for complex stratified flows [49-51] even though RANS models of stratified lake wind-induced circulation successfully captures internal wave motions and the resulting lateral flows $[3,22]$. Yet, the energy radiation and transport associated with internal waves and BBL flows are better represented by LES. In effect, an accurate description of the $\mathrm{BBL}$ is crucial to estimate the transport of water constituents such as dissolved oxygen [57] as well as to evaluate the potential of sediment transport [29, 72].

One of the most significant challenges of RANS models for predicting turbulent stratified flows is to include stratification effects in the expressions used to estimate the eddy viscosity and eddy diffusivity fields [53]. Indeed, the eddy diffusivity is usually assumed to be linearly related to the eddy viscosity (constant turbulent Prandtl or Schmidt numbers), which is a further important simplification in RANS. In time-accurate RANS, only the largest scales are resolved (e.g., those driven by the unsteady boundary condition at 
the free surface of a lake with unsteady wind) and the eddy viscosity and eddy diffusivity obtained via the RANS model have to account for the effect of all unresolved scales on the largest resolved ones. In LES we resolve most of the energetically important eddies in the flow, not only the largest. Moreover, when using a dynamic procedure to estimate the SGS viscosity and the SGS diffusivity based on the resolved velocity and density fields, the values of the SGS viscosity and SGS diffusivity are not necessarily correlated, which is physically correct [53]. The differences mentioned above are especially critical in stratified flows where the density distribution and mixing control the flow structure and the baroclinic oscillations, such as the internal waves. This is the case of the flow investigated in the present paper.

\section{Outlook}

The main environmental fluid mechanics outcomes of the present work are the following:

- We developed a simplified numerical model able to reproduce wind-driven stratified flows as well the magnitude and vertical distribution of key turbulence intensity quantities in a small and narrow stratified basin.

- This model allows a better understanding of the interplay between different physical processes working at diurnal scales.

- Specifically, we show the relevance of the cross-shore mass exchange driven by internal seiches interacting with the sloping bottom.

- Overall, the present study shows that eddy-resolving numerical simulations are a powerful tool to investigate a broad range of physical processes in stratified lakes. As highperformance computer power increases, LES becomes an alternative to RANS models and a feasible numerical approach to adopt for understanding the fundamental physics of stratified lakes.

Although we did not examine any specific ecological aspect, the outcomes of this study are relevant for linking physical and ecological processes that work at diurnal scale. Future research should consider the development of coupling high-resolution, physically-based numerical models with ecological models to explore physically-controlled ecological disturbances.

Acknowledgements This work has been developed during the sabbatical leave of George Constantinescu at EPFL. We acknowledge the financial contribution by the ENAC-EPFL Visiting Professor Program (Grant Number CF 0233). Discussions with Kraig B. Winters and Leo Maas on BBL dynamics and resonance regimes in stratified environments are gratefully acknowledged. We thank Javier Vidal for providing the Münnich's model that resolve the normal modes in an arbitrary 2-D stratified basin. We also thank Tomás Trewhela for his useful observations and criticisms on this work. The manuscript also benefited from feedback from two anonymous reviewers. Additional information on the model can be obtained by contacting G. Constantinescu at sconstan@engineering.uiowa.edu. 


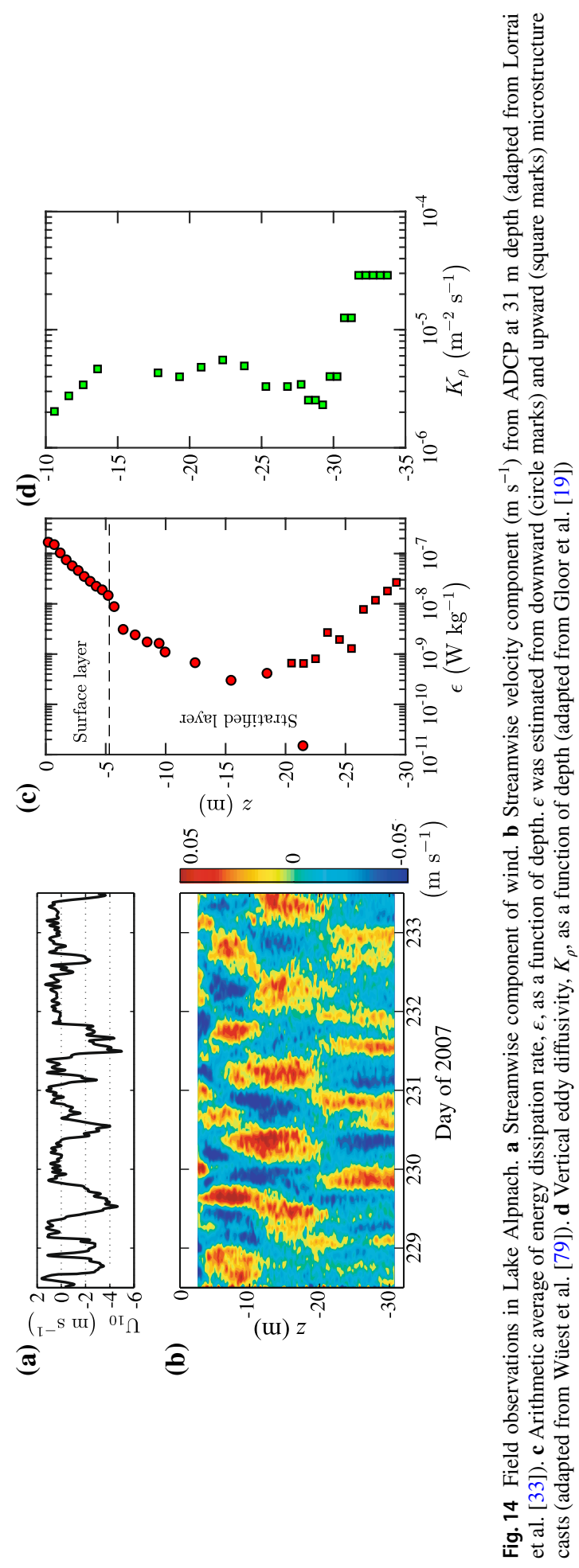




\section{Appendix 1: Observations in Lake Alpnach}

Lakes that count with reliable hydrodynamic observations are excellent candidates for assessing the performance of numerical models. Simultaneously, numerical models are excellent tools to extend the understanding of these systems via exploratory numerical experiments. Lake Alpnach (Switzerland) is an extensively investigated system since late 80's and is considered a real-scale laboratory to examine hydrodynamics and biogeochemical processes in lakes.

Figure 14 illustrates field observations of Lake Alpnach from different previous studies. Figure $14 \mathrm{a}, \mathrm{b}$ shows the wind speed, $U_{10}$, and velocity component, $u$, along the main lake axis (streamwise axis in our coordinate system). Winds show a diurnal structure while the streamwise velocity component has a robust baroclinic signature compound by three- and four-layer patterns with maximum/minimum values of order $u \approx \pm 0.05 \mathrm{~m} \mathrm{~s}^{-1}$. This flow structure has been well-reproduced via a realistic RANS simulation by Lorrai et al. [33] and by our idealized LES experiment (see Fig. 3). Figure 14c, d shows the average kinematic energy dissipation rate, $\varepsilon$, as a function of depth based on temperature microstructure profiles [79] and the estimation of the vertical eddy diffusivity, $K_{\rho}$, in the interior basin based on tracer dispersion tracking $[19,20]$, respectively. The laterally/time-averaged energy dissipation and vertical eddy diffusivity estimated from our numerical simulations (Fig. 12b, h) show reasonable agreement not only in the vertical structure but also in magnitudes.

\section{Appendix 2: Normal modes in a stratified trapezoidal basin}

The oscillatory normal modes and their natural frequencies are constrained to the stratification, boundary conditions, and the basin topography. Here, we investigate the normal modes of our system for classifying the observed internal wave field. To do so, we solve the eigenvalue problem for the 2 -D trapezoidal basin considering long wave approximation $[18,73]$ :

$$
\frac{\partial^{4} \psi}{\partial^{2} t \partial^{2} z}+N_{*}^{2}(z) \frac{\partial^{2} \psi}{\partial x^{2}}=0,
$$

where $\psi$ is the stream function. The streamwise and the vertical velocity components are determined by $u=-\partial \psi / \partial z$ and $w=\partial \psi / \partial x$, respectively. In this case, $N_{*}$ is the background stratification profile at the beginning of the ninth period (Fig. 4a). To resolve (16), we further assume an inviscid fluid and null normal velocities at the boundaries. We look for modal structures of the form $\psi=\Phi(x, z) e^{i(\omega t+\sigma)}$, where $\omega$ is the angular frequency of the mode and $\sigma$ an arbitrary wave phase. Then, Eq. (16) is reduced to

$$
\frac{\partial^{2} \Phi}{\partial^{2} x}-\frac{\omega^{2}}{N_{*}^{2}(z)} \frac{\partial^{2} \Phi}{\partial z^{2}}=0 .
$$

Equation (17) can be formulated as a generalized eigenvalue problem of the type $\mathbf{A} \Phi=\omega^{2} \mathbf{B} \Phi$, where $\mathbf{A}$ is a matrix characterized by the discretization on the streamwise axis $x$ and $\mathbf{B}$ is a matrix characterized by the discretization on the vertical axis $z$ and $N_{*}^{2}(z)$. Resolving the above eigenvalue problem provides the 2-D spatial structure of the normal modes, $\Phi(x, z)$, and their temporal structure established by $\omega$. Results are discussed in Sect. 3.1. 


\section{References}

1. Antenucci JP, Imberger J (2001) Energetics of long internal gravity waves in large lakes. Limnol Oceanogr 46(7):1760-1773. https://doi.org/10.4319/lo.2001.46.7.1760

2. Appt J, Imberger J, Kobus H (2004) Basin-scale motion in stratified upper Lake constance. Limnol Oceanogr 4(4):919-933. https://doi.org/10.4319/lo.2004.49.4.0919

3. Becherer JK, Umlauf L (2011) Boundary mixing in lakes: 1. Modeling the effect of shear-induced convection. J Geophys Res 116:C10017. https://doi.org/10.1029/2011JC007119

4. Bendat J, Piersol A (2000) Random data. Wiley, New York. https://doi.org/10.1002/9781118032428

5. Boegman L, Ivey GN, Imberger J (2005) The degeneration of internal waves in lakes with sloping topography. Limnol Oceanogr 50(5):1620-1637. https://doi.org/10.4319/lo.2005.50.5.1620

6. Boehrer B, Schultze M (2008) Stratification of lakes. Rev Geophys 46(2):RG2005. https://doi. org/10.1029/2006RG000210

7. Borden Z, Meiburg E, Constantinescu G (2012) Internal bores: an improved model via a detailed analysis of the energy budget. J Fluid Mech 703:279-314. https://doi.org/10.1017/jfm.2012.213

8. Bouffard D, Boegman L (2013) A diapycnal diffusivity model for stratified environmental flows. Dyn Atmos Oceans 61-62:14-34. https://doi.org/10.1016/j.dynatmoce.2013.02.002

9. Bouffard D, Boegman L, Rao YR (2012) Poincaré wave-induced mixing in a large lake. Limnol Oceanogr 57(4):1201-1216. https://doi.org/10.4319/lo.2012.57.4.1201

10. Chang K, Constantinescu G, Park SO (2006) Analysis of the flow and mass transfer processes for the incompressible flow past an open cavity with a laminar and a fully turbulent incoming boundary layer. J Fluid Mech 561:113-145. https://doi.org/10.1017/S0022112006000735

11. Chang K, Constantinescu G, Park SO (2007) Purging of a neutrally buoyant or a dense miscible contaminant from a rectangular cavity. II: case of an incoming fully turbulent overflow. J Hydraul Eng 133(4):373-385. https://doi.org/10.1061/(ASCE)0733-9429(2007)133:4(373)

12. Csanady GT (1982) On the structure of transient upwelling events. J Phys Oceanogr 12(1):84-96. https://doi.org/10.1175/1520-0485(1982)012<0084:OTSOTU>2.0.CO;2

13. de la Fuente A, Shimizu K, Niño Y, Imberger J (2010) Nonlinear and weakly nonhydrostatic inviscid evolution of internal gravitational basin-scale waves in a large, deep lake: lake constance. J Geophys Res Ocean. https://doi.org/10.1029/2009JC005839

14. Dittko KA, Kirkpatrick MP, Armfield SW (2013) Large eddy simulation of complex sidearms subject to solar radiation and surface cooling. Water Res 47(14):4918-4927. https://doi.org/10.1016/j.watre s.2013.05.045

15. Dorostkar A, Boegman L (2012) Internal hydraulic jumps in a long narrow lake. Limnol Oceanogr 58(1):153-172. https://doi.org/10.4319/1o.2013.58.1.0153

16. Dorostkar A, Boegman L, Pollard A (2017) Three-dimensional simulation of high-frequency nonlinear internal wave dynamics in Cayuga Lake. J Geophys Res Oceans 122(3):2183-2204. https://doi. org/10.1002/2016JC011862

17. Farrow DE (2013) Periodically driven circulation near the shore of a lake. Environ Fluid Mech 13(3):243-255. https://doi.org/10.1007/s10652-012-9261-4

18. Fricker PD, Nepf HM (2000) Bathymetry, stratification, and internal seiche structure. J Geophys Res 105(C6):14237-14251. https://doi.org/10.1029/2000JC900060

19. Gloor M, Wüest A, Imboden DM (2000) Dynamics of mixed bottom boundary layers and its implications for diapycnal transport in a stratified, natural water basin. J Geophys Res Oceans 105(C4):8629_ 8646. https://doi.org/10.1029/1999JC900303

20. Goudsmit GH, Peeters F, Gloor M, Wüest A (1997) Boundary versus internal diapycnal mixing in stratified natural waters. J Geophys Res Oceans 102(C13):27903-27914. https://doi.org/10.1029/97JC0 1861

21. Henderson SM (2016) Turbulent production in an internal wave bottom boundary layer maintained by a vertically propagating seiche. J Geophys Res Oceans 121(4):2481-2498. https://doi.org/10.1002/2015J C011071

22. Hodges BR, Imberger J, Saggio A, Winters KB (2000) Modeling basin-scale internal waves in a stratified lake. Limnol Oceanogr 45(7):1603-1620. https://doi.org/10.4319/lo.2000.45.7.1603

23. Hodges BR, Laval B, Wadzuk BM (2006) Numerical error assessment and a temporal horizon for internal waves in a hydrostatic model. Ocean Modell 13(1):44-64. https://doi.org/10.1016/j.ocemo d.2005.09.005

24. Hondzo M, Haider Z (2004) Boundary mixing in a small stratified lake. Water Resour Res. https://doi. org/10.1029/2002WR001851

25. Howard LN (1961) Note on a paper of John W Miles. J Fluid Mech 10(04):509-512. https://doi. org/10.1017/S0022112061000317 
26. Hutter K, Salvadè G, Spinedi C, Zamboni F, Bäuerle E (1991) Large scale water movements in lakes. Aquat Sci 53(2):100-135. https://doi.org/10.1007/BF00877057

27. Ivey GN, Winters KB, Koseff JR (2008) Density stratification, turbulence, but how much mixing? Annu Rev Fluid Mech 40(1):169-84. https://doi.org/10.1146/annurev.fluid.39.050905.110314

28. Keylock C, Hardy R, Parsons D, Ferguson R, Lane S, Richards K (2005) The theoretical foundations and potential for large-eddy simulation (LES) in fluvial geomorphic and sedimentological research. Earth Sci Rev 71(3-4):271-304. https://doi.org/10.1016/j.earscirev.2005.03.001

29. Keylock C, Constantinescu G, Hardy R (2012) The application of computational fluid dynamics to natural river channels: eddy resolving versus mean flow approaches. Geomorphology 179:1-20. https ://doi.org/10.1016/j.geomorph.2012.09.006

30. Lorke A (2007) Boundary mixing in the thermocline of a large lake. J Geophys Res 112:C09019. https ://doi.org/10.1029/2006JC004008

31. Lorke A, Umlauf L, Jonas T, Wüest A (2002) Dynamics of turbulence in low-speed oscillating bottom-boundary layers of stratified basins. Environ Fluid Mech 2(4):291-313. https://doi. org/10.1023/A:1020450729821

32. Lorke A, Peeters F, Wüest A (2005) Shear-induced convective mixing in bottom boundary layers on slopes. Limnol Oceanogr 50(5):1612-1619. https://doi.org/10.4319/lo.2005.50.5.1612

33. Lorrai C, Umlauf L, Becherer JK, Lorke A, Wüest A (2011) Boundary mixing in lakes: 2. Combined effects of shear- and convectively induced turbulence on basin-scale mixing. J Geophys Res 116:C10018. https://doi.org/10.1029/2011JC007121

34. Maas LRM, Lam FPA (1995) Geometric focusing of internal waves. J Fluid Mech 300:1-41. https:// doi.org/10.1017/S0022112095003582

35. Mahesh K, Constantinescu G, Moin P (2004) A numerical method for large-eddy simulation in complex geometries. J Comput Phys 197(1):215-240. https://doi.org/10.1016/j.jcp.2003.11.031

36. Mashayek A, Salehipour H, Bouffard D, Caulfield CP, Ferrari R, Nikurashin M, Peltier WR, Smyth WD (2017) Efficiency of turbulent mixing in the abyssal ocean circulation. Geophys Res Lett 44(12):6296-6306. https://doi.org/10.1002/2016GL072452

37. Miles JW (1961) On the stability of heterogeneous shear flows. J Fluid Mech 10(04):496-508. https:// doi.org/10.1017/S0022112061000305

38. Monismith SG (1985) Wind-forced motions in stratified lakes and their effect on mixed-layer shear. Limnol Oceanogr 30(4):771-783. https://doi.org/10.4319/1o.1985.30.4.0771

39. Monismith SG, Imberger J, Morison ML (1990) Convective motions in the sidearm of a small reservoir. Limnol Oceanogr 35(8):1676-1702. https://doi.org/10.4319/lo.1990.35.8.1676

40. Monsen NE, Cloern JE, Lucas LV, Monismith SG (2002) A comment on the use of flushing time, residence time, and age as transport time scales. Limnol Oceanogr 47(5):1545-1553. https://doi. org/10.4319/lo.2002.47.5.1545

41. Münnich M, Wüest A, Imboden DM (1992) Observations of the second vertical mode of the internal seiche in an alpine lake. Limnol Oceanogr 37(8):1705-1719. https://doi.org/10.4319/lo.1992.37.8.1705

42. Ooi SK, Constantinescu G, Weber L (2007) A numerical study of intrusive compositional gravity currents. Phys Fluids 19(7):076602. https://doi.org/10.1063/1.2750672

43. Ooi SK, Constantinescu G, Weber L (2009) Numerical simulations of lock-exchange compositional gravity current. J Fluid Mech 635:361-388. https://doi.org/10.1017/S0022112009007599

44. Osborn TR (1980) Estimates of the local rate of vertical diffusion from dissipation measurements. J Phys Oceanogr 10(1):83-89. https://doi.org/10.1175/1520-0485(1980)010<0083:EOTLR $\mathrm{O}>2.0 . \mathrm{CO} ; 2$

45. Petronio A, Roman F, Nasello C, Armenio V (2013) Large eddy simulation model for winddriven sea circulation in coastal areas. Nonlinear Process Geophys 20(6):1095-1112. https://doi. org/10.5194/npg-20-1095-2013

46. Pham HT, Sarkar S (2010) Transport and mixing of density in a continuously stratified shear layer. J Turbul 11:N24. https://doi.org/10.1080/14685248.2010.493560

47. Pierce CD, Moin P (2001) Progress-variable approach for large-eddy simulation of turbulent combustion. PhD thesis, Mechanical Engineering Department Report, TF-80, Standford University

48. Pierce CD, Moin P (2004) Progress-variable approach for large-eddy simulation of non-premixed turbulent combustion. J Fluid Mech 504:73-97. https://doi.org/10.1017/S0022112004008213

49. Piomelli U (2014) Large eddy simulations in 2030 and beyond. Philos Trans R Soc A 372(2022):20130320. https://doi.org/10.1098/rsta.2013.0320

50. Piomelli U, Chasnov JR (1996) Large-eddy simulations: theory and applications. Springer, Netherlands. https://doi.org/10.1007/978-94-015-8666-5_7

51. Pope SB (2000) Turbulent flows. Cambridge University Press, Cambridge. https://doi.org/10.1017/ CBO9780511840531 
52. Preusse M, Peeters F, Lorke A (2010) Internal waves and the generation of turbulence in the thermocline of a large lake. Limnol Oceanogr 55(6):2353-2365. https://doi.org/10.4319/lo.2010.55.6.2353

53. Rodi CGSTW (2013) Large-eddy simulation in hydraulics. CRC Press, London

54. Roman F, Stipcich G, Armenio V, Inghilesi R, Corsini S (2010) Large eddy simulation of mixing in coastal areas. Int J Heat Fluid Flow 31(3):327-341. https://doi.org/10.1016/j.ijheatfluidflow .2010 .02 .006

55. Rozas C, de la Fuente A, Ulloa H, Davies P, Niño Y (2014) Quantifying the effect of wind on internal wave resonance in Lake Villarrica, Chile. Environ Fluid Mech 14(4):849-871. https://doi. org/10.1007/s 10652-013-9329-9

56. Santo MA, Toffolon M, Zanier G, Giovannini L, Armenio V (2017) Large eddy simulation (LES) of wind-driven circulation in a peri-alpine lake: detection of turbulent structures and implications of a complex surrounding orography. J Geophys Res Ocean 122(6):4704-4722. https://doi. org/10.1002/2016JC012284

57. Scalo C, Boegman L, Piomelli U (2013) Large-eddy simulation and low-order modeling of sediment-oxygen uptake in a transitional oscillatory flow. J Geophys Res Oceans 118(4):1926-1939. https://doi.org/10.1002/jgrc.20113

58. Shih LH, Koseff JR, Ivey GN, Ferziger JH (2005) Parameterization of turbulent fluxes and scales using homogeneous shared stably stratified turbulence simulations. J Fluid Mech 525:193-214. https://doi.org/10.1017/S0022112004002587

59. Shintani T, de la Fuente A, Niño Y, Imberger J (2010) Generalizations of the Wedderburn number: parameterizing upwelling in stratified lakes. Limnol Oceanogr 55(3):1377-1389. https://doi. org/10.4319/1o.2010.55.3.1377

60. Simpson JH, Wiles PJ, Lincoln BJ (2011) Internal seiche modes and bottom boundary-layer dissipation in a temperate lake from acoustic measurements. Limnol Oceanogr 56(5):1893-1906. https ://doi.org/10.4319/1o.2011.56.5.1893

61. Sommer T, Danza F, Berg J, Sengupta A, Constantinescu G, Tokyay T, Bürgmann H, Dressler Y, Sepúlveda Steiner O, Schubert CJ, Tonolla M, Wüest A (2017) Bacteria-induced mixing in natural waters. Geophys Res Lett 44(18):9424-9432. https://doi.org/10.1002/2017GL074868

62. Spigel RH, Imberger $\mathrm{J}$ (1980) The classification of mixed-layer dynamics of lakes of small to medium size. J Phys Oceanogr 10(7):1104-1121. https://doi.org/10.1175/15200485(1980)010<1104:TCOMLD>2.0.CO;2

63. Steenhauer K, Tokyay T, Constantinescu G (2017) Dynamics and structure of planar gravity currents propagating down an inclined surface. Phys Fluids 29(3):036604. https://doi.org/10.1063/1.4979063

64. Taylor JR, Sarkar S (2008) Stratification effects in a bottom Ekman layer. J Phys Oceanogr 38(11):2535-2555. https://doi.org/10.1175/2008JPO3942.1

65. Tokyay T, Constantinescu G (2015) The effects of a submerged non-erodible triangular obstacle on bottom propagating gravity currents. Phys Fluids 27(5):056601. https://doi.org/10.1063/1.4919384

66. Tokyay T, Constantinescu G, Meiburg E (2011) Lock-exchange gravity currents with a high volume of release propagating over a periodic array of obstacles. J Fluid Mech 672:570-605. https://doi. org/10.1017/S0022112010006312

67. Tokyay T, Constantinescu G, Meiburg E (2012) Tail structure and bed friction velocity distribution of gravity currents propagating over an array of obstacles. J Fluid Mech 694:252-291. https://doi. org/10.1017/jfm.2011.542

68. Tokyay T, Constantinescu G, Meiburg E (2014) Lock-exchange gravity currents with a low volume of release propagating over an array of obstacles. J Geophys Res Oceans 119(5):2752-2768. https://doi. org/10.1002/2013JC009721

69. Ulloa HN, Winters KB, de la Fuente A, Niño Y (2015) Degeneration of internal Kelvin waves in a continuous two-layer stratification. J Fluid Mech 777:68-96. https://doi.org/10.1017/jfm.2015.311

70. Ulloa HN, Davis KA, Monismith SG, Pawlak G (2018) Temporal variability in thermally-driven cross-shore exchange: the role of semidiurnal tides. J Phys Oceanogr 48(7):1513-1531. https://doi. org/10.1175/JPO-D-17-0257.1

71. Valipour R, Bouffard D, Boegman L (2015) Parameterization of bottom mixed layer and logarithmic layer heights in central Lake Erie. J Great Lakes Res 41(3):707-718. https://doi.org/10.1016/j. jglr.2015.06.010

72. Valipour R, Boegman L, Bouffard D, Rao YR (2017) Sediment resuspension mechanisms and their contributions to high-turbidity events in a large lake. Limnol Oceanogr 62(3):1045-1065. https://doi. org/10.1002/lno.10485

73. Vidal J, Casamitjana X, Colomer J, Serra T (2005) The internal wave field in Sau reservoir: observation and modeling of a third vertical mode. Limnol Oceanogr 50(4):1326-1333. https://doi. org/10.4319/lo.2005.50.4.1326 
74. Vilhena LC, Marti CL, Imberger J (2013) The importance of nonlinear internal waves in a deep subalpine lake: Lake Iseo, Italy. Limnol Oceanogr 58(5):1871-1891. https://doi.org/10.4319/ lo.2013.58.5.1871

75. von Kármán T (1931) Mechanical similitude and turbulence. Technical report, Technical memorandum, Report No 611. NACA, Washington D.C

76. Wain DJ, Kohn MS, Scanlon JA, Rehmann CR (2013) Internal wave-driven transport of fluid away from the boundary of a lake. Limnol Oceanogr 58(2):429-442. https://doi.org/10.4319/ lo.2013.58.2.0429

77. Winters KB (2015) Tidally driven mixing and dissipation in the stratified boundary layer above steep submarine topography. Geophys Res Lett 42(17):7123-7130. https://doi.org/10.1002/2015GL064676

78. Wüest A, Lorke A (2003) Small-scale hydrodynamics in lakes. Annu Rev Fluid Mech 35(1):373-412. https://doi.org/10.1146/annurev.fluid.35.101101.161220

79. Wüest A, Piepke G, Van Senden DC (2000) Turbulent kinetic energy balance as a tool for estimating vertical diffusivity in wind-forced stratified waters. Limnol Oceanogr 45(6):1388-1400. https://doi. org/10.4319/lo.2000.45.6.1388

80. Yuksel-Ozan A, Constantinescu G, Nepf H (2016) Free-surface gravity currents propagating in an open channel containing a porous layer at the free surface. J Fluid Mech 809:601-627. https://doi. org/10.1017/jfm.2016.698

\section{Affiliations}

\section{Hugo N. Ulloa ${ }^{1} \cdot$ George Constantinescu² ${ }^{2}$ Kyoungsik Chang ${ }^{3}$. Daniel Horna-Munoz ${ }^{2,4}$. Oscar Sepúlveda Steiner ${ }^{1}$. Damien Bouffard ${ }^{5}$. Alfred Wüest ${ }^{1,5}$}

George Constantinescu

sconstan@engineering.uiowa.edu

Kyoungsik Chang

kschang76@ulsan.ac.kr

Daniel Horna-Munoz

dhorna@utec.edu.pe

Oscar Sepúlveda Steiner

oscar.sepulvedasteiner@epfl.ch

Damien Bouffard

damien.bouffard@eawag.ch

Alfred Wüest

alfred.wueest@eawag.ch

1 Physics of Aquatic Systems Laboratory, Margaretha Kamprad Chair,

École Polytechnique Fédérale de Lausanne, 1015 Lausanne, Switzerland

2 Civil and Environmental Engineering, IIHR-Hydroscience and Engineering, The University of Iowa, Iowa City, IA 52242, USA

3 School of Mechanical Engineering, University of Ulsan, Ulsan, South Korea

4 Environmental Engineering Department, Centro de Investigación y Tecnología del Agua (CITA), Universidad de Ingeniería y Tecnología (UTEC), Barranco, Lima, Peru

5 Surface Waters - Research and Management, Eawag, Swiss Federal Institute of Aquatic Science and Technology, CH-6047 Kastanienbaum, Switzerland 